\title{
The Case Study of Combined Cooling Heat and Power and Photovoltaic Systems for Building Customers Using HOMER Software
}

\author{
Insu Kim $^{1 *}$, Jean-Ann James ${ }^{2}$, John Crittenden ${ }^{2}$
}

\begin{abstract}
Combined heat and power (CHP) systems such as microturbines with capacities in the range of tens of kilowatts to hundreds of kilowatts have been employed for many years, mostly in residential, commercial, and industrial buildings. Despite their relatively small individual capacities as compared to centralized conventional utilities, their operation may lead to significant energy efficiency improvements for the electricity and heating of residential and commercial building customers. In addition, modern net-zero energy buildings with such CHP, photovoltaic (PV) systems, and absorption chillers (AbCs) can maximize electrical and thermal energy efficiency as they can reuse wasted heat from CHP systems with AbCs and renewable energy from PV systems. Therefore, the objective of this study is to present a case study that analyzes the impact of combined cooling heat and power (CCHP) of building customers either with or without PV systems in energy-efficient, economical, and environmental aspects. Then, using HOMER
\end{abstract}


software, a computer program for modeling renewable microgrid systems, each case study of residential buildings hosting only CCHP systems in the Atlanta area and office buildings hosting CCHP and PV systems in the area is simulated. Finally, their energy-efficiency improvement and economic sensitivity analysis on investment costs of CCHP and PV systems is presented.

\section{Key Words}

Absorption chiller (AbC), combined cooling heat and power (CCHP), HOMER, microturbine (MT), and photovoltaic (PV) system. 


\section{Introduction}

Combined heat and power (CHP) systems, particularly systems which utilize microturbines (MTs) as the prime mover, can simultaneously produce electricity and heat at efficiencies of 65 percent to 75 percent [1]. Therefore, they have been employed for many years, mostly in commercial and industrial applications. For example, the central power plant at the University of Michigan has a capacity of 45.2 megawatts and is the first system in the United States that has produced electricity, cooling, and steam energy using natural gas since 1914 [2]. Nowadays, modern net-zero energy buildings improve electrical and thermal energy efficiency as they reuse wasted heat from CHP systems with absorption chillers (AbCs) and renewable energy from photovoltaic (PV) systems.

During the last a few decades, many studies have analyzed the impact of the CHP system on reducing energy consumption and air emissions for residential, commercial, and industrial customers. The previous work for analyzing the impact of the CHP system can be typically classified as (a) reviewing the various computer programs available for analyzing the integration of the CHP system, (b) solving the optimal dispatch of energy hubs, including CHP systems, and (c) analyzing their effects on reducing energy consumption and emissions such as carbon dioxide $\left(\mathrm{CO}_{2}\right)$ and nitrogen oxides $\left(\mathrm{NO}_{\mathrm{x}}\right)$.

In the first approach, various computer programs, including HOMER, evaluation methods, and indicators were reviewed from the point of view of energy usage, emission reduction, and operating costs [3-5]. In the second approach, one study defined the second-order output functions for power and heat and formulated an optimal dispatch problem for CHP systems to minimize total generation costs, using a genetic algorithm [6]. Another study investigated the combination of PV, CHP, and battery storage that supplies an electric grid in the Kingston area (Ontario in Canada) 
with base power and they found that the CHP system should operate more than 20 hours a day for such a combination system to run effectively [7]. Also, another study modeled a CHP system with an $\mathrm{AbC}$ (to meet cooling load) and an auxiliary boiler with a heat storage tank and determined the optimal energy flow of each module to maximize the total benefits of the CHP system for a day as a case study [8]. The Lyapunov optimization techniques were recently used to solve an optimal scheduling problem of CHP systems (that use natural gas, biomass, and geothermal energy) to minimize average energy costs with the constraints of real-time electricity prices. The results of the study showed that the optimal scheduling of CHP systems enhanced by a battery system and a water tank (to store heat) could save average energy costs, particularly by approximately 27 to 29 percent in the case study [9].

While the previous studies have modeled and optimized CHP systems, one study proposed an "energy hub" concept in power-flow, reliability, system optimization, the evaluation of investment, and application aspects [10]. Then, the power flow of various energy hub models, including a CHP system, was optimized $[11,12]$. Recently, one study developed a model for the predictive control strategy that could mitigate failures in energy hub networks and applied the proposed model to the 132-node energy hub model [13]. Using MATLAB and CPLEX optimization libraries, another study presented an optimization framework that analyzes large energy hub networks that consist of electrical networks, natural gas networks, heat loads, and wind generators [14]. Using mixed integer linear programming (MILP) techniques, some studies solved a mathematic optimization problem for a residential energy hub with residential energy loads, storage, and production components such as generic models for solar PV panels, energy storage, and generation devices $[15,16]$. Recently, one study analyzed the characteristics of harbor energy systems, optimized the energy flow of a harbor energy hub to minimize energy consumption, and 
presented an universal framework that models multiple-energy carriers [17]. From the numerical simulations of the proposed model, one study determined the most proper investment candidates for expanding an energy hub model that consists of CHP and natural gas furnaces and supplies electricity, natural gas, and heating loads [18]. Another study presented the power-to-gas technology that enhances power system operability and converts electrical energy to hydrogen or methane based on an energy hub and applied the proposed method to historic data [19].

While the previous studies have focused on specific energy hubs, recently, integrated energy hub models for various energy systems and demand response have been proposed in [20, 21]. However, the long-term, or annul, operation of combined cooling heat and power (CCHP) systems with both $\mathrm{AbC}$ and PV systems is not examined in any of these previous studies. Therefore, this study will schedule their optimal dispatch for one year to examine the effect of CCHP systems on energy efficiency, using as input data electrical and thermal load profile data collected from the case study.

In the last approach, or analyzing the effects of CHP systems on reducing energy consumption and emissions, one study performed a quantitative analysis for CHP systems in operation over 15 years for office building applications (with a floor area of 24,000 $\mathrm{m}^{2}$ ) in Beijing [22]. It claimed that in the case study CHP systems could reduce the costs of equipment and energy (by about 8 percent), primary energy consumption (by about 5.8 percent), and $\mathrm{CO}_{2}$ emissions (by about 25 percent) [22]. Another study investigated the potential for harnessing the heat lost from national electricity generation in the United States and demonstrated that if the heat can be recovered by waste heat recovery systems, it can reduce the total energy usage of the nation by 12 percent and the release of $\mathrm{CO}_{2}$ by as much as 13 percent [23]. More recently, another study examined waste heat recovery systems that run an $\mathrm{AbC}$, which provides chilled air that cools 
server equipment at a data center (that consumes about 30 percent of electricity to cool server equipment). From the six case studies, they claimed that such a system with AbCs could reduce the energy usage of the data center by up to 23 percent $[24,25]$.

All these previous studies have indicated that CHP systems could improve electrical and thermal energy efficiency as they use waste heat, particularly CHP systems with AbCs. However, they did not examine residential customers with CHP systems with an AbC (CHP-AbC) and modern office buildings hosting PV systems on their rooftops and CHP-AbC from the standpoint of long-term, typically annual, operation. In fact, among renewables, PV systems may be uniquely suited to rooftops of office buildings. In addition, CHP-AbC can provide not only chilled water or air from waste heat for hot days but also heating or hot water for cold days. Therefore, the objective of this study is to present a case study that examines the effect of the CHP-AbC of building customers either with or without PV systems on a reduction in: (a) energy consumption, (b) costs of generating electrical and thermal energy, (c) emissions (such as $\mathrm{CO}_{2}, \mathrm{NO}_{\mathrm{X}}$, and sulfur dioxide $\left.\left[\mathrm{SO}_{2}\right]\right)$, and (d) water consumption.

This paper is organized as follows: Section 2 describes the problem statement; Section 3 models a power and thermal grid enhanced by CHP, PV systems, and AbCs; Section 4 introduces case studies that use the proposed simulation model. Section 5 discusses the simulation results of the case study; and then Section 6 summarizes the major conclusions and contributions of this study on the energy-efficient, economic, and environmental impact of CCHP systems.

\section{Problem Statement}

To analyze the effects of the CCHP system, particularly using MTs and AbCs, on building customers either with or without PV systems, this study proposes the following two scenarios: 
1) Constant output of a CCHP system. MTs for building customers either with or without PV systems constantly operate at its maximum capacity for base power load.

2) Optimal operation of a CCHP system. MTs optimally operate in order to minimize energy costs during one year.

For this purpose, this study models a hypothetical electric and thermal grid of residential and office buildings hosting CHP-AbC and PV. Fig. 1 shows an example of the CCHP system of an office building that is connected to the electric power grid, the central thermal utility (that provides natural gas to the boiler of the office building), MTs, AbCs, and PV systems. In electrical energy flow, plotted by the dash-dotted lines, MTs, rooftop PV systems, and the electric power utility supply electrical energy to the office building. In thermal energy flow, plotted by the dashed lines, MTs, AbCs, and the central thermal utility supply thermal energy to the building. For example, for summer days, the CCHP system with AbCs can provide chilled water or air from waste heat with an $\mathrm{AbC}$ and for winter days, space heating and hot water, thereby maximizing energy efficiency. The energy performance improvement caused by the CCHP system with AbC and PV systems is modeled in the following section.

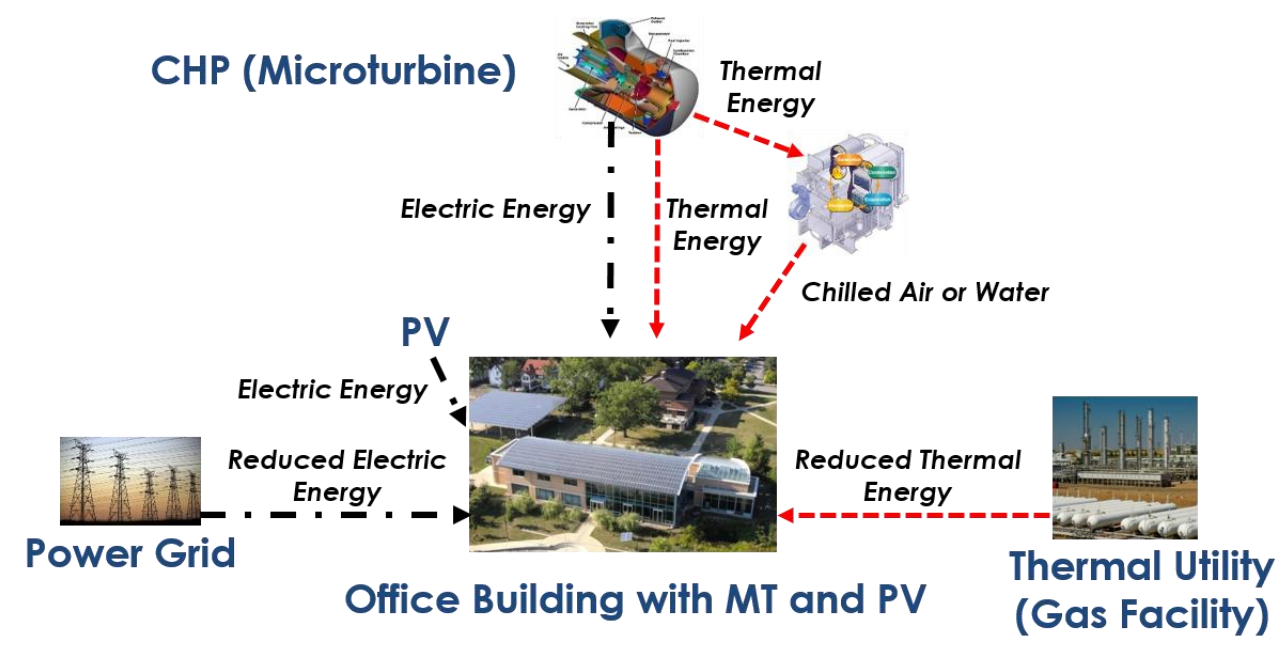

Fig. 1. Example of the CCHP system with the electric power grid, the thermal utility, and the PV system for building customers. 


\section{CHP and PV Systems}

\subsection{HOMER}

HOMER is a computer analysis program useful for modeling hybrid renewable microgrid systems, including wind turbines, fuel cells, hydropower, biomass, converters, batteries, conventional generators, PV, and CHP systems [26]. To determine the optimal size of components of either stand-alone or grid-connected microgrids, the program takes six types of input data, including (a) meteorological data (wind speed, solar radiation, temperature, hydro, and steam flow data), (b) hourly or sub-hourly electric and thermal demand profile data, (c) economic cost data (operation and maintenance cost, capital cost, replacement cost, fuel price, transaction electricity price, interest rate, lifetime, system fixed capital cost, maintenance cost, and emissions penalty), (d) technical data (dispatch strategy and operating reserve), (e) equipment characteristics data, and (f) search space [5]. Using the input data, HOMER examines all the feasible configuration of such hybrid renewable microgrid systems with an objective function that minimizes total net present cost subtracted by revenues from the sum of costs [27]. Then, it selects the most feasible solution that satisfies constraints specified in the input data (e.g., minimum and maximum capacities, fuel prices, and costs for generating electricity) at the lowest total costs.

\subsection{Modeling of a Power and Thermal Grid Enhanced by CHP Systems}

This study uses HOMER to schedule the optimal electric and thermal power output of CHP systems during one year in hourly intervals. The following equation describes a total penetration capacity of either CCHP or PV systems:

$$
\text { Penetration in } \%=\frac{\sum_{i \in\{\text { Case Study }\}} P_{P, i}}{P_{\text {Peak }}},
$$


where $P_{P, i}=$ the power of CCHP or PV system $i$ in $\mathrm{kW}$ or MW, $P_{P e a k}=$ the total peak power of a case study in $\mathrm{kW}$ or MW.

\subsection{Microturbines}

This study uses a C65 Capstone MT generator as an example of the CHP system. An input-output model of a MT generator in Fig. 2 is linearized by the following first-order equation:

$$
P_{i}=a_{i} F_{i}+b_{i}
$$

where

$P_{i}=$ the power output of microturbine $i$ in $\mathrm{kW}$, typically 25 to $500 \mathrm{~kW}$,

$F_{i}=$ the fuel input of microturbine $i$ in $l /$ hour.

Equation (2) is linearized by the linear least-squares method from the data points. For example, the MT produces an electric output of $65 \mathrm{~kW}$ and a thermal output of 408,000 BTU by burning natural gas [28]. The detailed parameters for a MT generator are presented in the Appendix. This study assumes a lifetime of 80,000 hours and predicts its performance using the HOMER program (version 2.68).

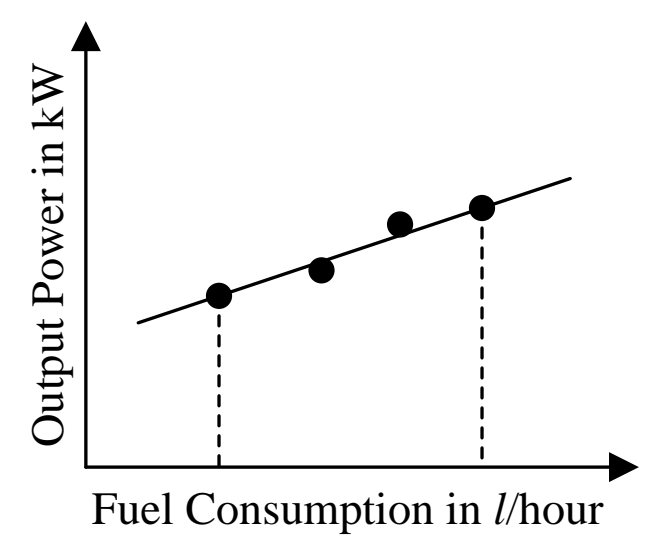

Fig. 2. Input-output characteristics of fuel curve of a microturbine. 


\subsection{Absorption Chiller}

AbCs use waste heat to run the refrigeration cycle so that they can produce chilled water or air. The thermal output (e.g., chilled air or water) of AbCs could not be determined by HOMER because it does not provide an $\mathrm{AbC}$ model. Thus, this study theoretically estimates the thermal output $\left(P_{A b C}\right)$ of AbCs with loss coefficients such as a performance coefficient of 0.75 and a pipe loss coefficient of 0.9 [29] when recovering chilled air or water from the waste heat emitted from MTs. In fact, if AbCs recover chilled air and water, a CCHP system does not require cooling energy from electric utilities. Thus, in the case study simulations, this study subtracts the cooling demand $\left(P_{A b C}\right)$ unnecessary as a result of the operation of AbCs from the original electric demand $\left(P_{O r i}\right)$. That is, the final modified demand data $\left(P_{\text {Demand }}\right)$ are

$$
P_{\text {Demand }}=P_{O r i}-P_{A b C} \text {, }
$$

where

$P_{O r i}=$ the original electrical demand data for either residential or office building customers in $\mathrm{kW}$, $P_{A b C}=$ the theoretical thermal output data able to be recovered by AbCs in $\mathrm{kW}$.

And then, these patterned demand data are used as input data to HOMER for the following case studies.

\section{Case Studies}

To present a case study that analyzes the impact of CCHP and PV systems on building customers, this study uses the Atlanta area as a metropolitan city. Then, this study initially presents a case study of residential building customers in the area that host a power and thermal grid system enhanced by CHP systems with AbCs but without PV (because of economical reasons). As a second case study, this study models a CCHP system of office buildings in the area with PV 
systems. The detailed equations and system models that the case studies use for PV and CHP systems are presented in [26] and the detailed simulation parameters are presented in the Appendix.

\section{1. $\quad$ Electric and Thermal Load Profile}

Since load (or demand) varies instantaneously according to customer demand, this study collects load (or demand) data of various building types of the case study during 2013 (for a single home) and 2004 (for 16 commercial building types) in hourly intervals from Open Energy Information (OpenEI) [30]. They include residential (e.g., a single home and mid-rise apartment) and commercial (small and large hotels, small, medium, and large offices, stand-alone retail, strip mall, super market, warehouse, primary and secondary schools, hospital, outpatient health care, quick-service, and full-service restaurants) customers. TABLE I shows an annual summary of load profile data of each building type in the Atlanta area. For example, Fig. 3 presents electric and thermal load profiles of a single home in the area. The load profile shows an electric peak of 4.13 $\mathrm{kW}$ on August 1 at a load factor of 0.36 in (a) and (c) and a thermal peak of $13.3 \mathrm{~kW}$ on February 12 at a load factor of 0.09 in (b) and (d). The load factor is the ratio of the average load (or demand) to the peak load over a given period. 
TABLE I. Electric and thermal load data of each building type in the Atlanta area

\begin{tabular}{|c|c|c|c|c|c|c|}
\hline \multirow{2}{*}{ Type } & \multicolumn{3}{|c|}{ Electric Data } & \multicolumn{3}{c|}{ Thermal Data } \\
\cline { 2 - 7 } & Peak(kW) & Date & Energy(MWh/year) & Peak(kW) & Date & Energy(MWh/year) \\
\hline Single Home & 4.1 & $8 / 1$ & 13.0 & 13.3 & $2 / 12$ & 10.0 \\
\hline Small Office & 19.4 & $7 / 7$ & 68.2 & 26.0 & $2 / 13$ & 7.5 \\
\hline Quick-Service Restaurant & 39.1 & $7 / 7$ & 199.6 & 84.6 & $2 / 12$ & 213.3 \\
\hline Mid-Rise Apartment & 69.2 & $7 / 7$ & 258.8 & 117.1 & $2 / 12$ & 107.8 \\
\hline Full-Service Restaurant & 70.5 & $7 / 7$ & 334.4 & 152.3 & $2 / 12$ & 381.6 \\
\hline Warehouse & 95.8 & $8 / 1$ & 261.9 & 217.0 & $2 / 3$ & 130.3 \\
\hline Strip Mall & 101.9 & $7 / 7$ & 316.0 & 225.5 & $1 / 13$ & 109.2 \\
\hline Stand-Alone Retail & 112.7 & $7 / 7$ & 349.2 & 252.5 & $2 / 11$ & 97.0 \\
\hline Small Hotel & 135.4 & $8 / 18$ & 624.1 & 89.2 & $2 / 12$ & 197.9 \\
\hline Medium Office & 264.4 & $2 / 13$ & 728.6 & 80.5 & $2 / 3$ & 18.0 \\
\hline Outpatient Health Care & 318.2 & $7 / 6$ & 1414.9 & 208.2 & $1 / 13$ & 783.3 \\
\hline Primary School & 338.3 & $6 / 23$ & 936.7 & 768.8 & $2 / 13$ & 263.0 \\
\hline Super Market & 375.5 & $7 / 8$ & 1771.1 & 607.2 & $2 / 12$ & 489.0 \\
\hline Large Hotel & 464.5 & $8 / 25$ & 2590.1 & 988.8 & $2 / 12$ & 2254.6 \\
\hline Secondary School & 1250.5 & $6 / 6$ & 3710.6 & 2791.5 & $2 / 13$ & 1034.4 \\
\hline Hospital & 1544.8 & $12 / 4$ & 10016.5 & 1172.9 & $2 / 13$ & 3642.3 \\
\hline Large Office & 1620.1 & $5 / 26$ & 6963.5 & 2877.1 & $2 / 13$ & 419.4 \\
\hline
\end{tabular}

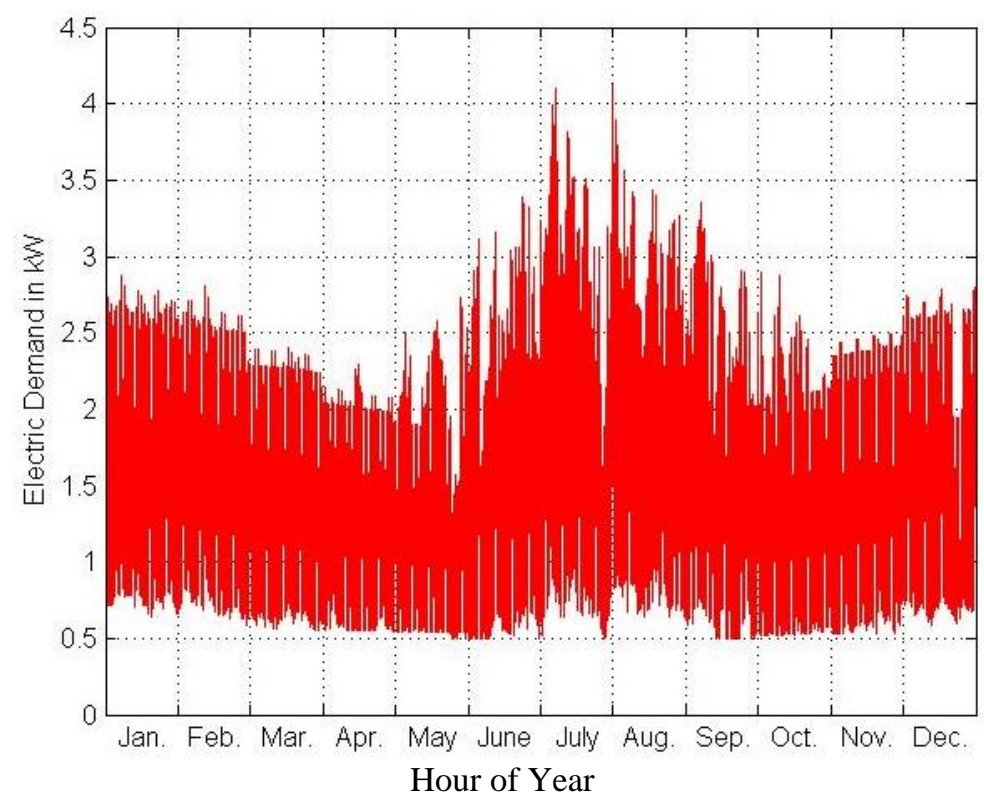

(a) Instantaneous electric demand during one year in hourly intervals 


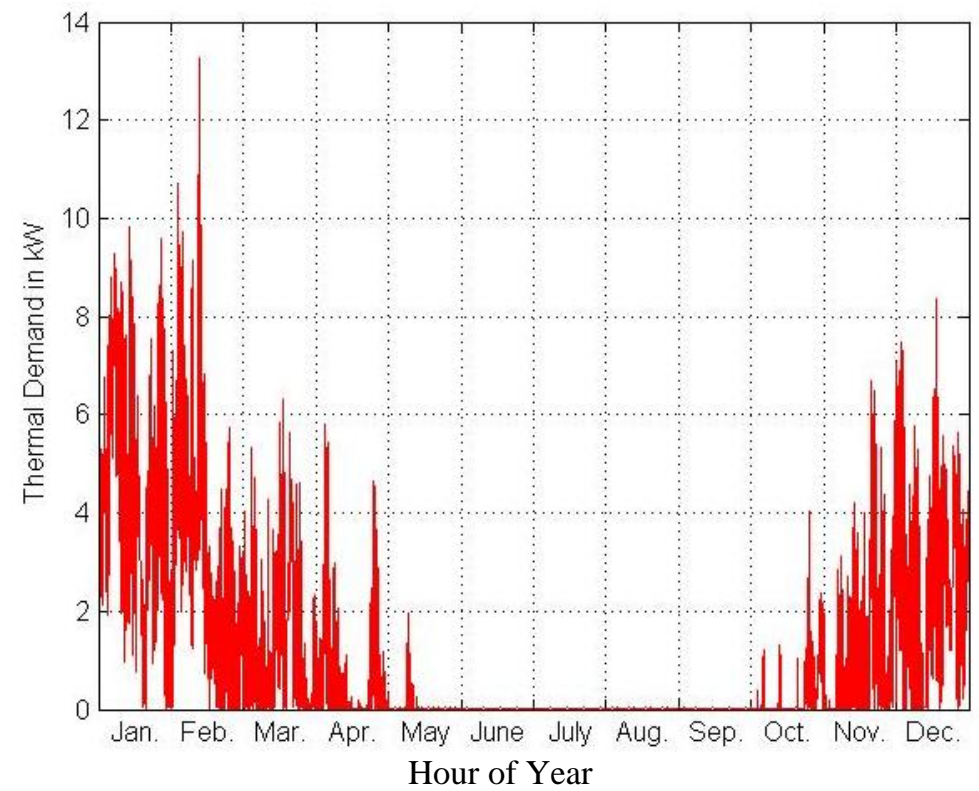

(b) Thermal demand during one year in hourly intervals

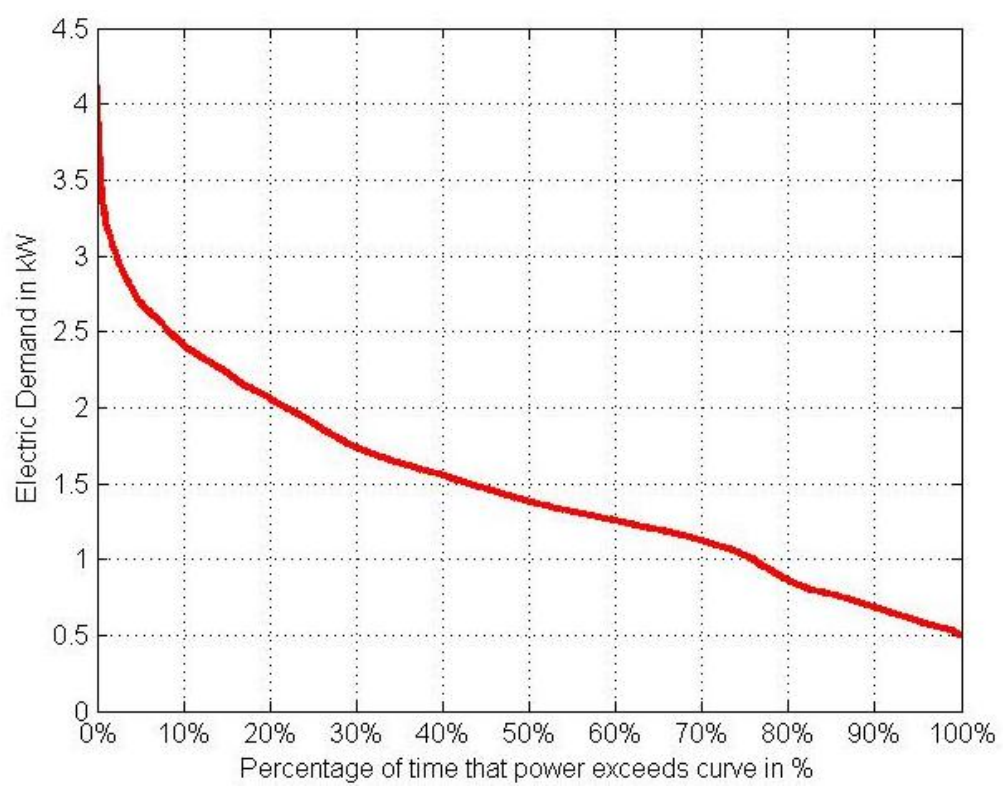

(c) Duration curve of electric demand during one year 


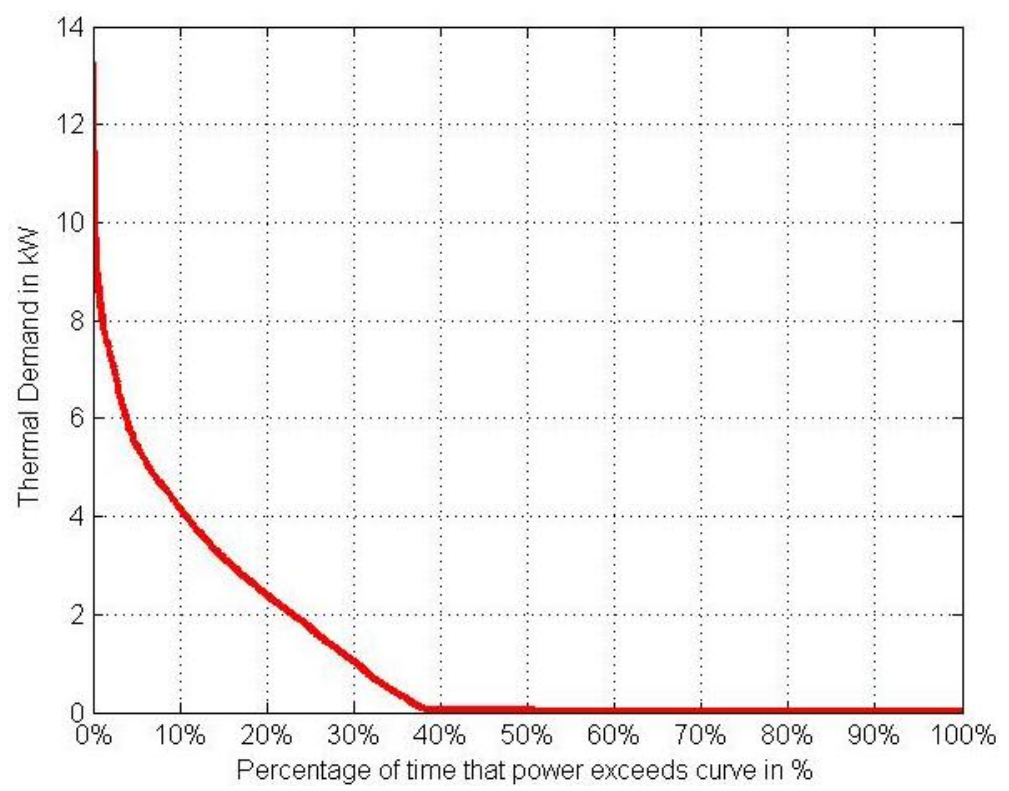

(d) Duration curve of thermal demand during one year

Fig. 3. An example of electric and thermal load profiles in the Atlanta area.

\subsection{Building Customers without PV Systems}

Since CCHP systems installed in the Atlanta area are still not available for the proposed case study, this study initially examines Masonic Village in Elizabethtown, Pennsylvania that has installed six 65-kW Capstone MTs for the residential facility [31]. To determine the effect of MTs with AbCs on residential customers in the Atlanta area, this study assumes that a similar community in the area is enhanced by the same MTs as Masonic Village installed. To model a power and thermal grid for this Atlanta community, electric and thermal load profile data for residential customers in the Atlanta area are collected from OpenEI. Since Masonic Village serves 1,700 residents, or 669 residential households $(\approx 1,700 / 2.54)$ if 2.54 people per household [32] and the total active power of the Atlanta community is approximated by multiplying load profile data for a residential home collected from OpenEI [30] by 669. Therefore, the synthesized load profile data show an electric peak of $2,762 \mathrm{~kW}$ and a thermal peak of $8,884.94 \mathrm{~kW}$. The penetration level of CCHP systems that consist of six C65 65-kW Capstone MTs, totally $390 \mathrm{~kW}$, for the proposed 
Atlanta area is $14.1 \%$, which is $(65 \mathrm{~kW} \times 6) /(4.13 \mathrm{~kW} \times 669)$ by equation (1) and corresponds to the recommended limit, or 15 percent of the peak load proposed in [33].

If $\mathrm{AbCs}$ produce chilled water or air from waste heat, residential building customers do not need energy for cooling from the electric utility. In Fig. 4, this study scatters total cooling loads of 669 residential customers, which can be reduced by such AbCs that recover cooled air or water from waste heat within its capacity limit. To analyze the economic impact of CCHP systems on costs for generating energy, this study uses the cost data in TABLE II as input data to the proposed simulation model in HOMER. The average of generation costs for Georgia Power Company is 42.27 \$/MWh in 2010 [34]. The natural gas price is $0.12 \$ / \mathrm{m}^{3}$ in 2012 [35]. The production cost for MTs with an $\mathrm{AbC}$ is $\$ 778.26 / \mathrm{kW}[8]$.

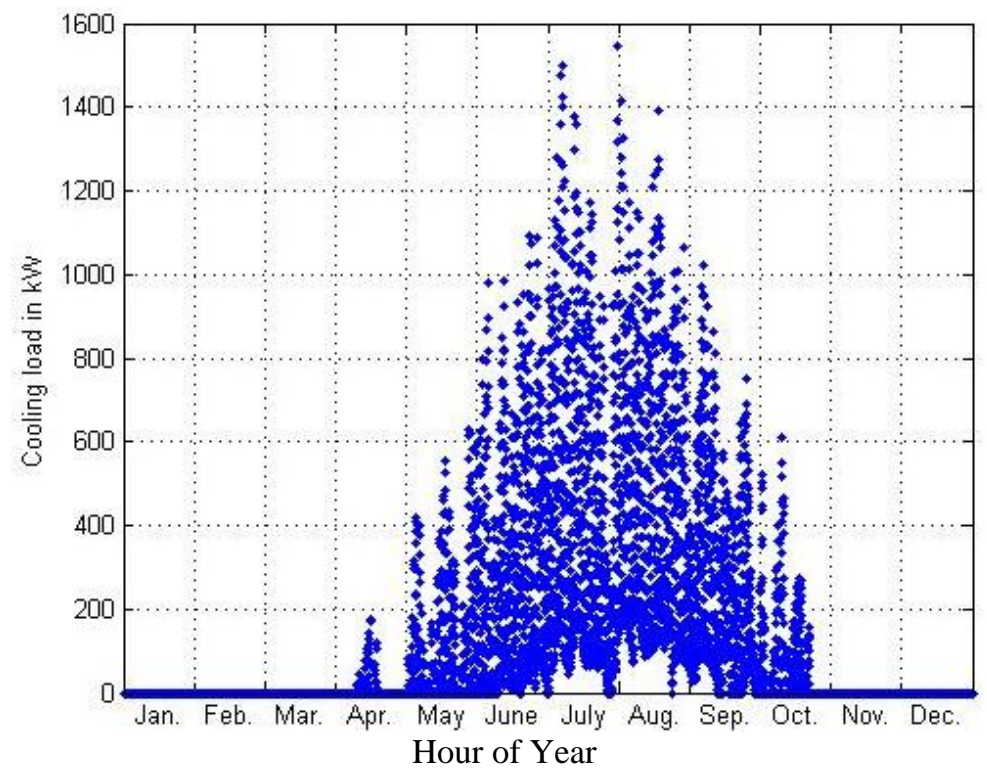

Fig. 4. Total cooling load of 699 households during one year in the Atlanta area.

TABLE II. Generation cost data for a case study for residential customers

\begin{tabular}{|c|c|c|c|}
\hline \multicolumn{3}{|c|}{ Type } & Cost \\
\hline \multicolumn{3}{|c|}{ Average of Generation Costs for Georgia [34] } & $42.27 \$ / M W h$ \\
\hline \multicolumn{3}{|c|}{ Natural Gas Price for Electric Power in Georgia [35] } & $0.12 \$ / \mathrm{m}^{3}$ \\
\hline Costs of $65-\mathrm{kW}$ Microturbine & Capital (\$) & Replacement (\$) & Maintenance (\$) \\
\hline With Chiller [8] & $\$ 50,587$ & $\$ 50,587$ & $0.01 \$ /$ hour \\
\hline
\end{tabular}




\subsection{Office Building Customers with PV Systems}

Since office buildings hosting both CCHP and PV systems in the Atlanta area are still not available for the proposed case study, this study initially examines an office building in Manhattan, New York in 2006 that has installed 12 65-kW Capstone MTs [36]. To determine the effect of MTs with an AbC and PV systems on office building customers in the Atlanta area, this study assumes that the office buildings are enhanced by the same as those in the office in Manhattan, New York. Then, a power and thermal grid of the CCHP system is modeled by HOMER (version 2.68). Then, this study collects hourly electric, cooling, and thermal load profile data for small, medium, and large office building customers in the Atlanta area from OpenEI [30], determines the electric output of PV systems based on solar irradiation to the area, and schedules the electric and thermal output of MTs to meet electric and thermal demand of the customers.

Both the total capacities of CCHP and PV systems in TABLE III correspond to the recommended limit on the total capacity of distributed generation systems, or 15 percent of the peak load [33]. To be consistent on the capacity of CCHP and PV systems, this study selects the number of 65-kW Capstone MTs to meet such 15 percent of total peak demand of all the buildings in each building type. To analyze the economic impact of CCHP and PV systems on office building customers, this study uses generation costs presented in TABLE IV, which are used as input data to the proposed simulation model in HOMER. The production cost of $\$ 4.30 / \mathrm{W}$ for the PV system [37, 38] and $\$ 778.26 / \mathrm{kW}$ for MTs with an AbC are used [8, 29, 39]. 
TABLE III. Small, medium, and large office buildings (Atlanta) [30, 33, 40]

\begin{tabular}{|c|c|c|c|}
\hline Size & Small & Medium & Large \\
\hline Number of Floors & 1 & 3 & 12 \\
\hline Floor Area in $\mathrm{ft}^{2}$ & 5,500 & 53,628 & 498,588 \\
\hline Electric Peak & $19.4 \mathrm{~kW}(\mathrm{Jul} / 07)$ & $264.4 \mathrm{~kW}(\mathrm{Feb} / 13)$ & $1,620.1 \mathrm{~kW}($ May/26) \\
\hline Thermal Peak & $26.0 \mathrm{~kW}(\mathrm{Feb} / 13)$ & $80.5 \mathrm{~kW}(\mathrm{Feb} / 03)$ & $2,877.1 \mathrm{~kW}(\mathrm{Feb} / 13)$ \\
\hline Number of Buildings & 22 & 5 & 4 \\
\hline CCHP Type & \multicolumn{3}{|c|}{ C65 65-kW Capstone Microturbine } \\
\hline The Number of MTs & 1 & 3 & 15 \\
\hline Penetration $\%$ of MTs from Peak & $\frac{65 \mathrm{~kW} \times 1}{19.4 \mathrm{~kW} \times 22} \approx 15.2 \%$ & $\frac{65 \mathrm{~kW} \times 3}{264.4 \mathrm{~kW} \times 5} \approx 14.8 \%$ & $\frac{65 \mathrm{~kW} \times 15}{1,620.1 \mathrm{~kW} \times 4} \approx 15.0 \%$ \\
\hline Total Capacity of PVs & $65 \mathrm{~kW}$ & $195 \mathrm{~kW}$ & $975 \mathrm{~kW}$ \\
\hline Penetration $\%$ of PVs from Peak & $\frac{65 \mathrm{~kW}}{19.4 \mathrm{~kW} \times 22} \approx 15.2 \%$ & $\frac{195 \mathrm{~kW}}{264.4 \mathrm{~kW} \times 5} \approx 14.8 \%$ & $\frac{975 \mathrm{~kW}}{1,620.1 \mathrm{~kW} \times 4} \approx 15.0 \%$ \\
\hline PV Location & \multicolumn{3}{|c|}{ Atlanta (Facing South) and 30 Years } \\
\hline
\end{tabular}

TABLE IV. Generation cost data for a case study for office buildings

\begin{tabular}{|c|c|c|}
\hline System & Type & Cost \\
\hline Central Grid [34] & Fuel Price $(\$ / \mathrm{MWh})$ & $42.27 \$ / \mathrm{MWh}$ \\
\hline Central Thermal Utility [35] & Fuel Price $\left(\$ / \mathrm{m}^{3}\right)$ & $0.12 \$ / \mathrm{m}^{3}$ \\
\hline \multirow{2}{*}{ 65-kW PV [37, 38] } & Capital $(\$)$ & $\$ 279,500$ \\
\cline { 2 - 3 } & Replacement $(\$)$ & $\$ 279,500$ \\
\cline { 2 - 3 } & O\&M $(\$ /$ year) & $475 \$ /$ year \\
\hline \multirow{2}{*}{$65-\mathrm{kW}$ PV Inverter [41] } & Capital $(\$)$ & $\$ 16,000$ \\
\cline { 2 - 3 } & Replacement $(\$)$ & $\$ 16,000$ \\
\cline { 2 - 3 } & O\&M $(\$ /$ year) & $1,528 \$ /$ year \\
\cline { 2 - 3 } & Capital $(\$)$ & $\$ 50,587$ \\
\hline \multirow{2}{*}{$65-\mathrm{kW}$ Microturbine (with Chiller) [8, 29,39] } & Replacement $(\$)$ & $\$ 50,587$ \\
\hline
\end{tabular}

\section{Simulation Results}

\subsection{Residential Customers without PV Systems}

\subsubsection{Energy Efficiency Improvement}

A C65 MT can produce both electric and thermal energy at peak hours, at which energy is usually created by burning expensive fuel. In Fig. 5 (a), the total electric load (or demand) of 669 residential customers in the Atlanta area is composed of cooling, fans, electric heater or furnace for heating, lights, and equipment on an electric peak day, or on August 1, 2013. Since the cooling demand usually dominates other demands on summer days, an AbC can recover chilled air from waste heat. In the scenario of MTs in constant operation at their maximum capacity, six AbCs recover cooling air of $485.32 \mathrm{kWh}(\approx 408,000$ BTUs $\times 6 \times 0.75 \times 0.90)$. For example, in Fig. 5 (b), six 
C65 MTs that constantly operate at their maximum capacity produce a chilled air output of 485.32 $\mathrm{kW}$ and an electricity output of $390 \mathrm{~kW}(=65 \mathrm{~kW} \times 6)$. However, in Fig. 5 (c), only three MTs intermittently produce chilled air of $242 \mathrm{~kW}(\approx 408,000$ BTUs $\times 3 \times 0.75 \times 0.90)$ and electricity of 195 $\mathrm{kW}(=65 \mathrm{~kW} \times 3)$ while minimizing the costs of generating energy.

Fig. 6 shows the hourly thermal output of the boiler and MTs for heating and the chilled air output of MTs on the same day, August 1, 2013. In Fig. 6 (a), since six MTs that constantly operate at their maximum capacity produce a chilled air output of $485.32 \mathrm{~kW} \quad(\approx 408,000$ BTUs $\times 6 \times 0.75 \times 0.90)$, the CCHP system does not require heating energy from the thermal utility (or the boiler) before 9 a.m. However, since the cooling demand increases after 9 a.m., the CCHP system recovers chilled air by running AbCs, so the system requires heat energy from the thermal utility from 9 a.m. to 9 p.m. Fig. 6 (b) indicates that three MTs in optimal operation intermittently produce only chilled air while minimizing the costs of generating energy. In fact, in the optimal operation scenario, since the three MTs provide the system with chilled air at peak hours, the system does not require expensive electrical energy from the grid that burns expensive fossil fuel.

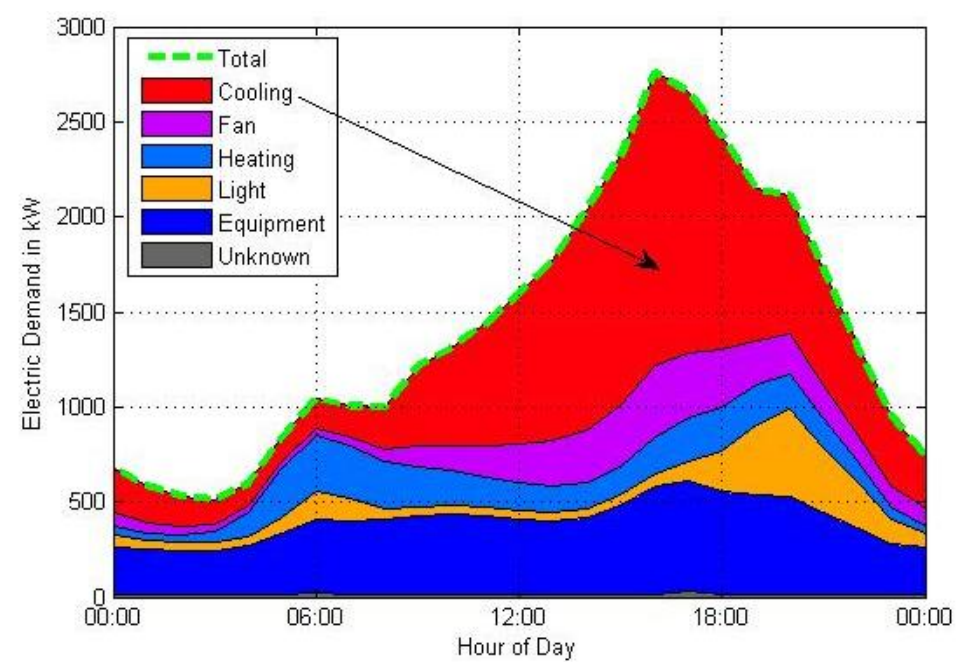

(a) Electric demand 


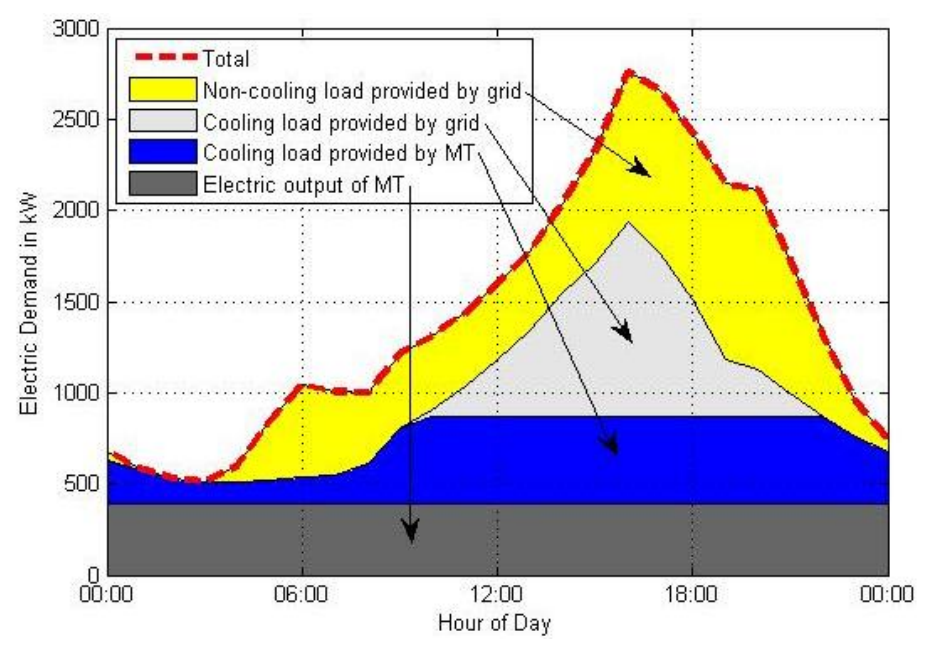

(b) Constant output scenario

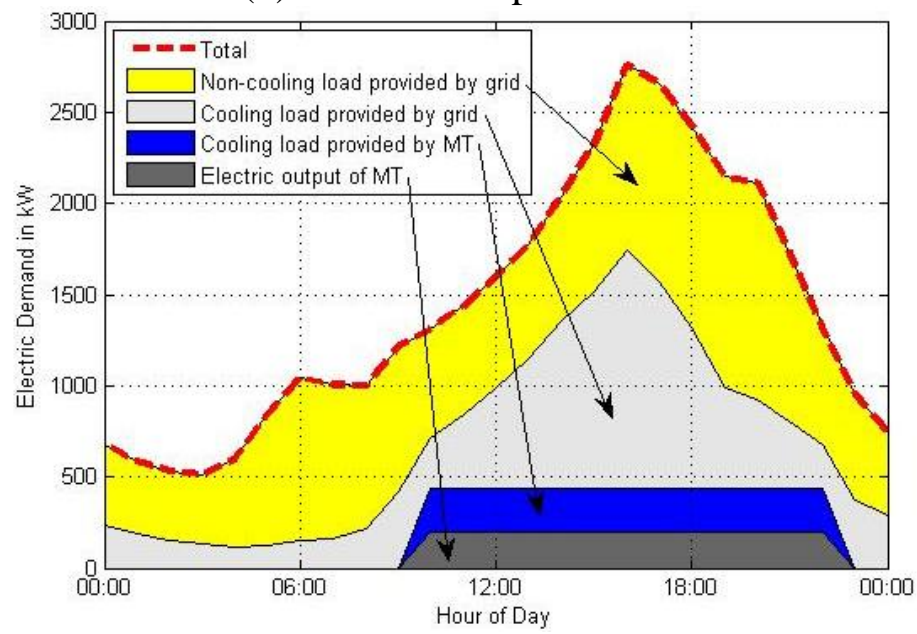

(c) Optimal output scenario

Fig. 5. Electric output (for base power) and chilled air output (for cooling demand) of Capstone MTs on an electric peak day, Aug. 1, 2013.

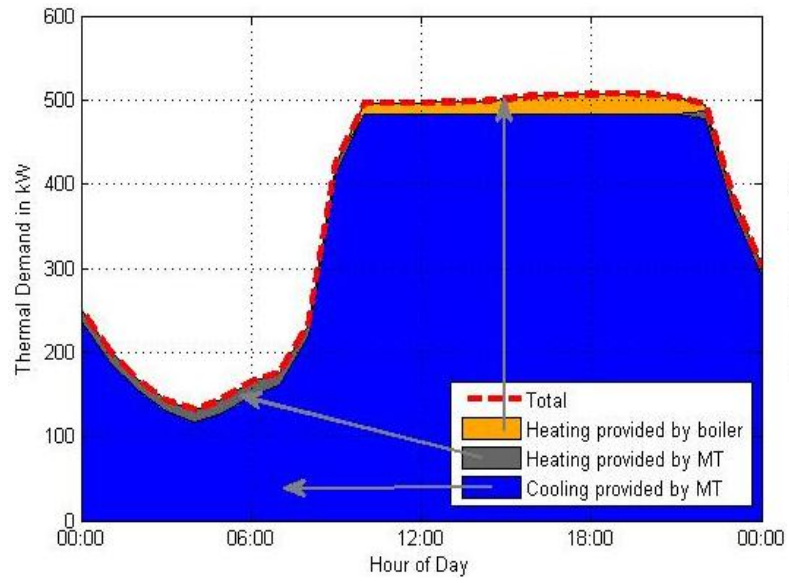

(a) Constant output scenario

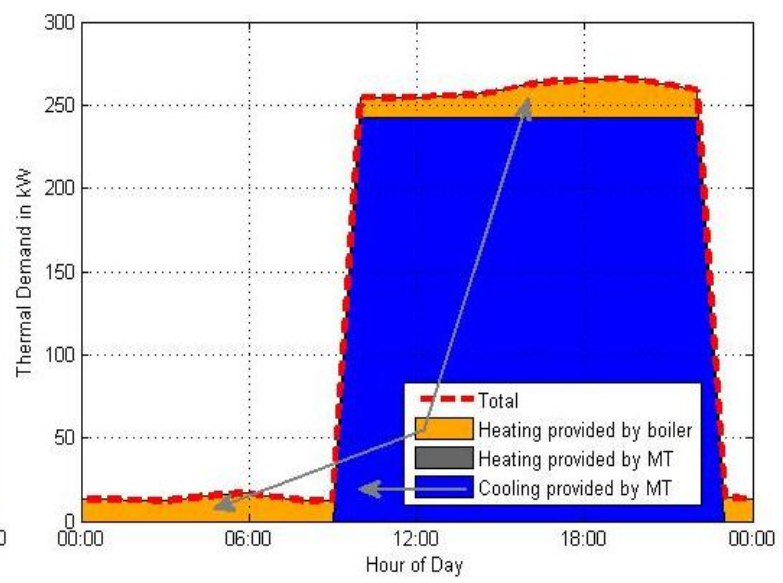

(b) Optimal output scenario

Fig. 6. Thermal output (for heating) and chilled air output (retrieved from AbCs) of MTs on Aug. $1,2013$. 
Fig. 7 illustrates the thermal output of MTs on a thermal peak day, Feb. 12, 2013. In the constant operation scenario, six MTs that constantly operate at their maximum capacity generate a thermal energy of $717.44 \mathrm{kWh}(\approx 408,000 \mathrm{BTUs} \times 6)$. In the optimal operation scenario, the three MTs generate a thermal energy of $358.72 \mathrm{kWh}(\approx 408,000 \mathrm{BTUs} \times 3)$.

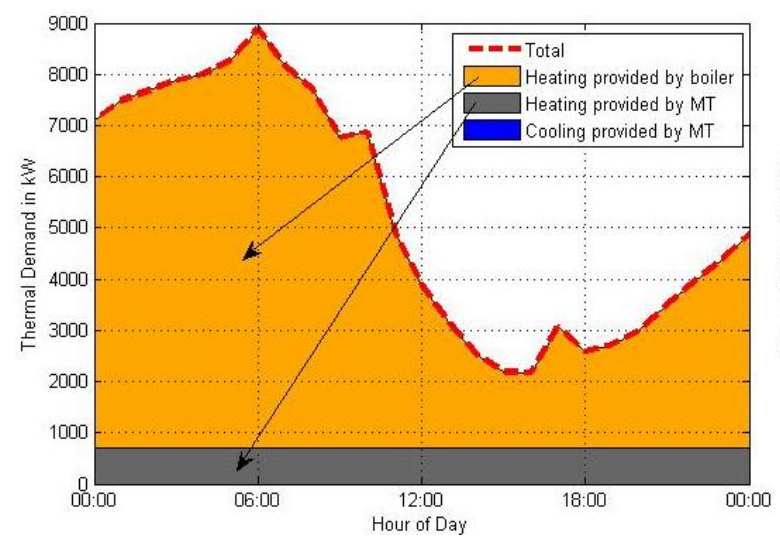

(a) Constant output scenario

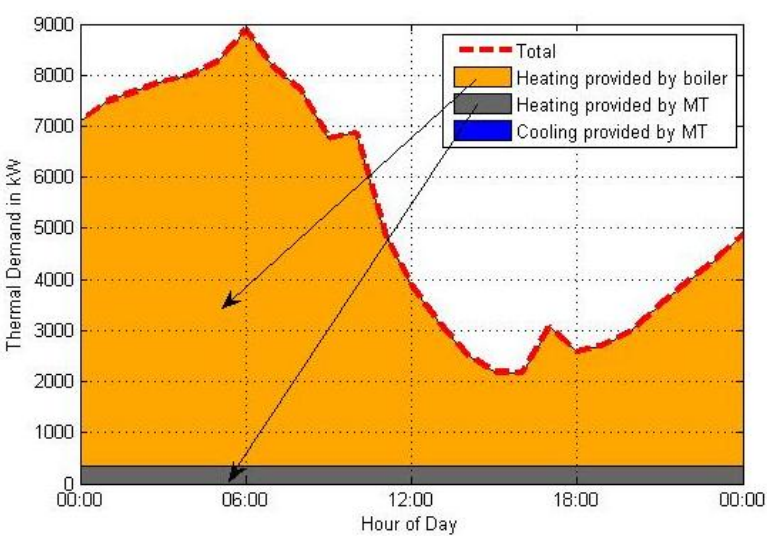

(b) Optimal output scenario

Fig. 7. Thermal output for heating of MTs on Feb. 12, 2013.

After performing the simulations of operation of MTs during one year, an annual summary of electric energy purchased from the electric utility is presented in Fig. 8. The orange, blue, and green bars correspond to the cases of (a) without MTs, (b) full-blast MTs (with AbCs), and (c) optimal-blast MTs (with AbCs), respectively. Fig. 8 illustrates that the constant operation of MTs with AbCs (Full-blast MT w/ Chiller) at their full capacity can decrease annual electric energy provided from the power grid by as much as 48.8 percent. In fact, on summer days, the CCHP system generates both electricity and chilled air because the cooling demand is the highest and its generation costs are the most expensive. On the contrary, on winter days, MTs produce mostly heat and electricity, not chilled air. 


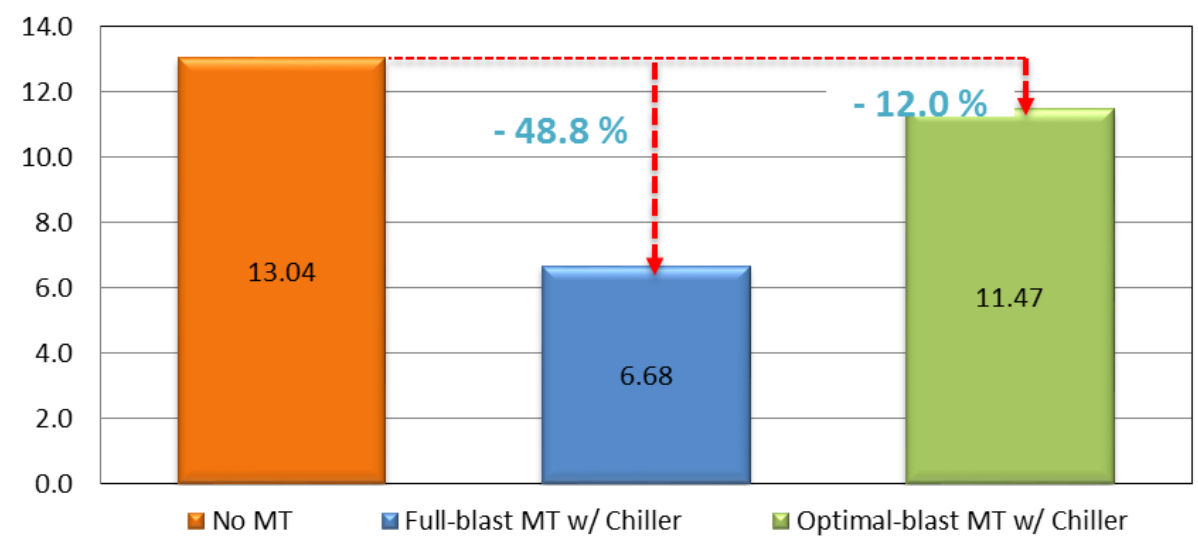

Fig. 8. Electric energy output purchased from the utilities in MWh/year/household.

\subsubsection{Economic Impact}

For some scenarios, MTs with AbCs can affect the costs of generating electric and thermal energy. From an economic sensitivity analysis on investment and operation costs performed by HOMER, Fig. 9 indicates that MTs in constant operation (Full-blast MT w/ Chiller) can save total generation costs by as much as 0.82 percent and MTs in optimal operation to minimize costs (Optimal-blast MT w/ Chiller) can save 5.55 percent. Thus, MTs in optimal operation are more economical than those in constant operation. Fig. 10 shows the economic sensitivity analysis on investment costs of the MTs. For example, as average costs for generating electricity (or the power price in the Y-axis of Fig. 10) in $\$ / \mathrm{kWh}$ increase, in other words, as vertically moving from the lower to the upper area, and natural gas prices in $\$ / \mathrm{m}^{3}$ decrease, in other words, as horizontally moving from the right to the left area, relatively higher-capacity MTs, the capacity of which is given in the legend bar from $0 \mathrm{~kW}$ to 400 in $40 \mathrm{~kW}$ intervals, can be cost-effectively installed on. In this case study for residential customers, MTs with a capacity of 160 to $200 \mathrm{~kW}$, pointed out by the white dashed arrows, or three $65-\mathrm{kW}$ MTs $(\approx 65 \mathrm{~kW} \times 3=195 \mathrm{~kW})$, are the most cost effective, or optimal, at a natural gas price of $0.12 \$ / \mathrm{m}^{3}$ and a power price of $0.042 \$ / \mathrm{kWh}$. 


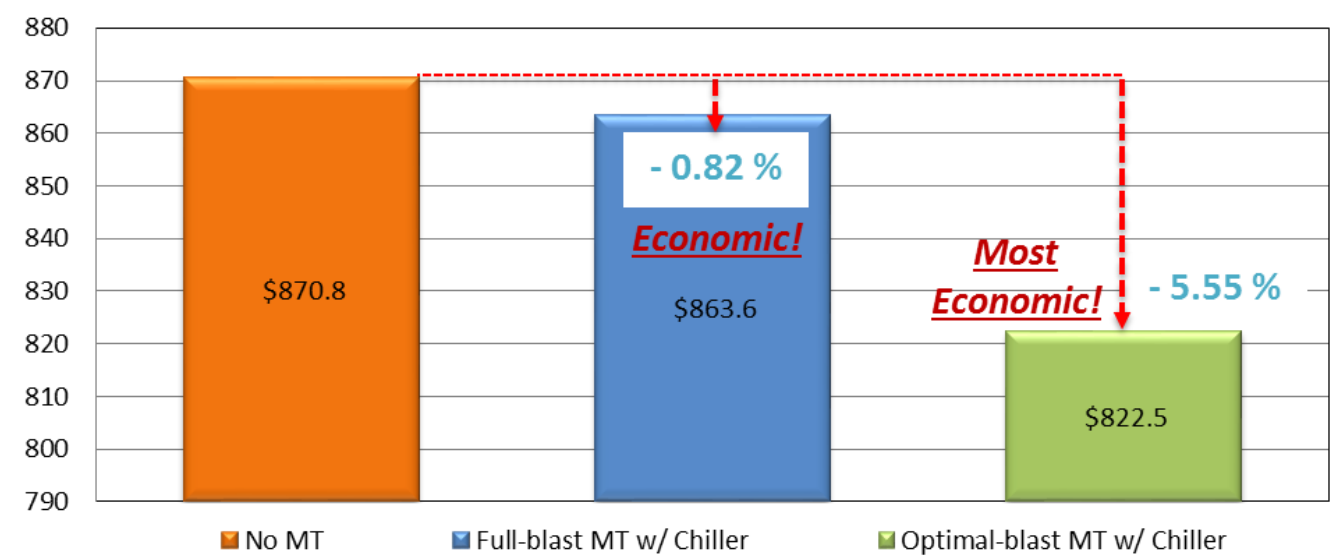

Fig. 9. Total annualized generation costs in \$/year/household (including investment costs of

CCHP systems).

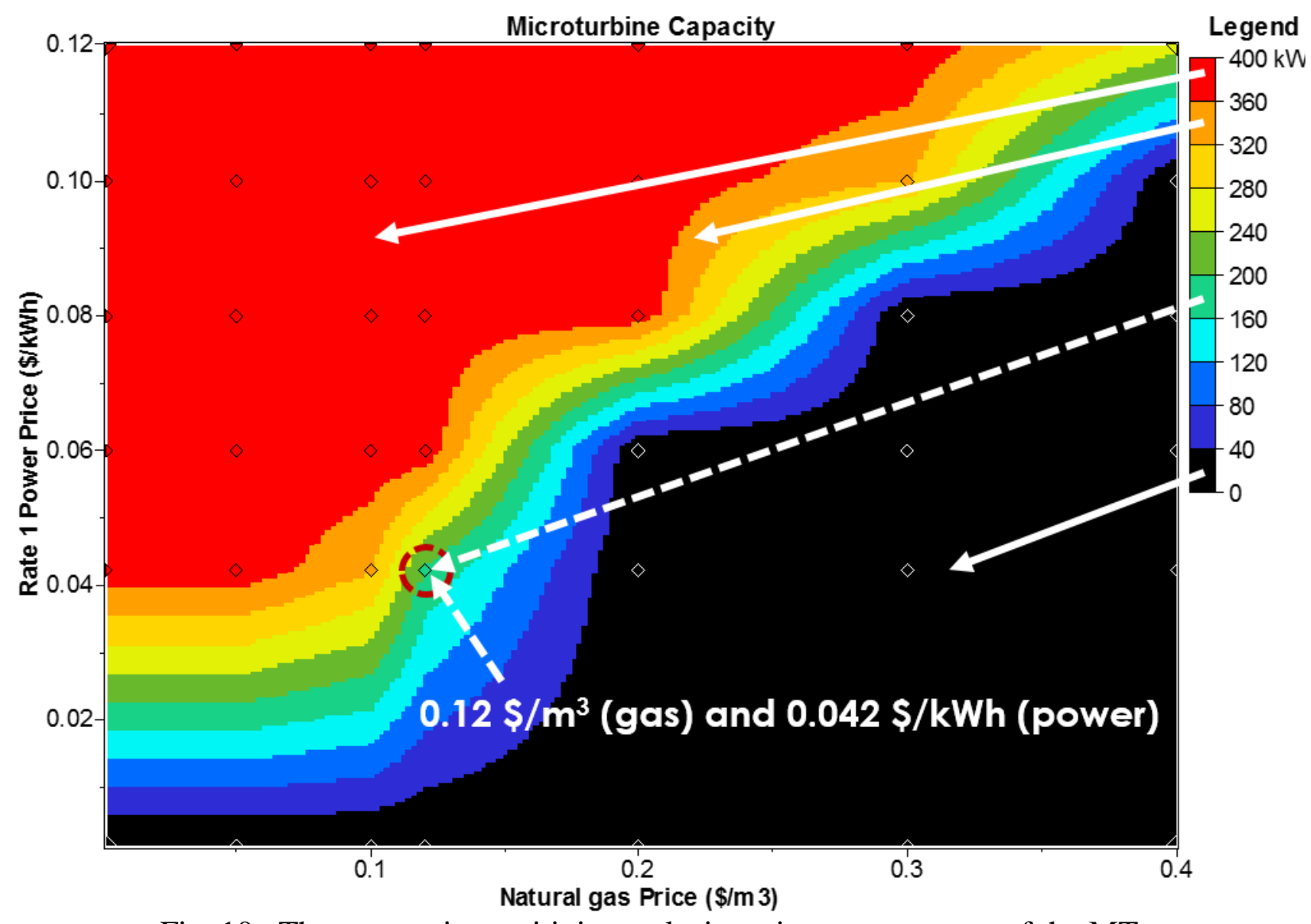

Fig. 10. The economic sensitivity analysis on investment costs of the MTs.

\subsubsection{Environmental Impact}

Since the CCHP system uses less fossil fuel than conventional fossil-fuel power generation plants, it can release less greenhouse gases and other pollutants. The water coefficients consumed 
by each fossil-fuel type for producing electric energy correspond to the amount of water that is required for cooling and only accounts for evaporation. $2.77 \mathrm{l} / \mathrm{kWh}$ for coal-fired, $1.13 \mathrm{l} / \mathrm{kWh}$ for gas-fired, $3.45 l / \mathrm{kWh}$ for nuclear, and 179.50 l/kWh for hydroelectric generation are used [29, 42]. Water evaporated by MTs is zero [43]. Since HOMER could not estimate water evaporation, this study determines the water evaporation output by the coefficients. The detailed other emission coefficients for $\mathrm{CO}_{2}, \mathrm{NO}_{\mathrm{X}}$, and $\mathrm{SO}_{2}$ are presented in [44]. These coefficients are used as input data to HOMER that estimates annual emissions output. Fig. 11 presents only the annual environmental impact of MTs on water consumption. In fact, in the proposed case study of residential customers without PV systems, the CCHP system in constant operation at their maximum capacity (Full-blast MT w/ Chiller) reduces $\mathrm{CO}_{2}, \mathrm{NO}_{\mathrm{X}}, \mathrm{SO}_{2}$, and water consumption (evaporation) by as much as 15.5 , $38.1,16.8$, and 48.6 percent, respectively. For the optimal operation scenario, the system reduces $\mathrm{CO}_{2}, \mathrm{NO}_{\mathrm{X}}, \mathrm{SO}_{2}$, and water consumption by $9.2,7.7,9.5$, and 12.0 percent respectively.

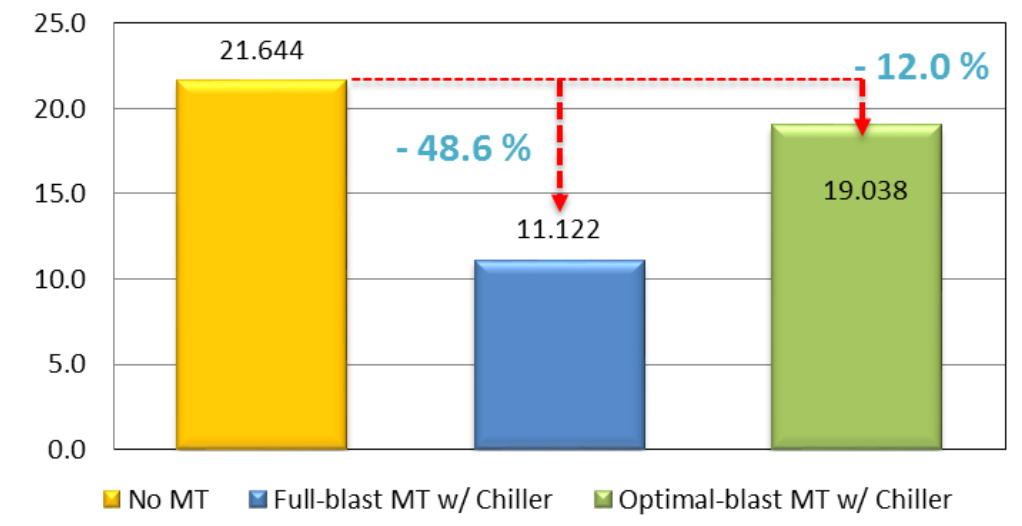

Fig. 11. Annual water consumption of MTs in kgal/year/household.

\subsection{Office Building Customers with PV}

\subsubsection{Energy Efficiency Improvement}

As an example of CCHP with PV, this study collects the electric demand of small, medium, and large office building customers in the Atlanta area, which is composed of cooling, fans, 
electric heater or furnace, lights, and interior equipment. For example, Fig. 12 (a) presents a total electrical demand profile of four large office buildings in the Atlanta area on an electric peak day, or May 26, 2004. Since the cooling demand dominates the others and it usually occurs at peak hours, the CCHP system runs an $\mathrm{AbC}$ to recover chilled air from waste heat. Therefore, on summer days, the system produces chilled air or water so that it can avoid purchasing cooling energy, the generation costs of which are usually more expensive. In the scenario of four large office buildings and fifteen MTs at their full capacity, AbCs can recover cooling energy of 1,210.68 kWh $(\approx 408,000$ BTUs $\times 15 \times 0.75 \times 0.9)$. For example, in Fig. 12 (b), fifteen C65 MTs that constantly operate (at their maximum capacity) produce a chilled air output of $1,210.68 \mathrm{~kW}$ and an electric energy output of $975 \mathrm{~kW}(=65 \mathrm{~kW} \times 15)$. However, in Fig. 12 (c), only ten MTs intermittently generate an electric output of $650 \mathrm{~kW}(=65 \mathrm{~kW} \times 10)$ and a chilled air output of $807.12 \mathrm{~kW}$ $(\approx 408,000$ BTUs $\times 10 \times 0.75 \times 0.9)$ during about only fifteen hours while minimizing the costs of producing energy. In Fig. 12 (b) and (c), the C65 MTs and PV systems for large office building customers effectively decrease the peak demand from 7 a.m. to 8 p.m., which usually burns expensive fuel. The generation output of PV systems is estimated by solar radiation amount to the Atlanta area [45]. The detailed data for the PV system are presented in the Appendix.

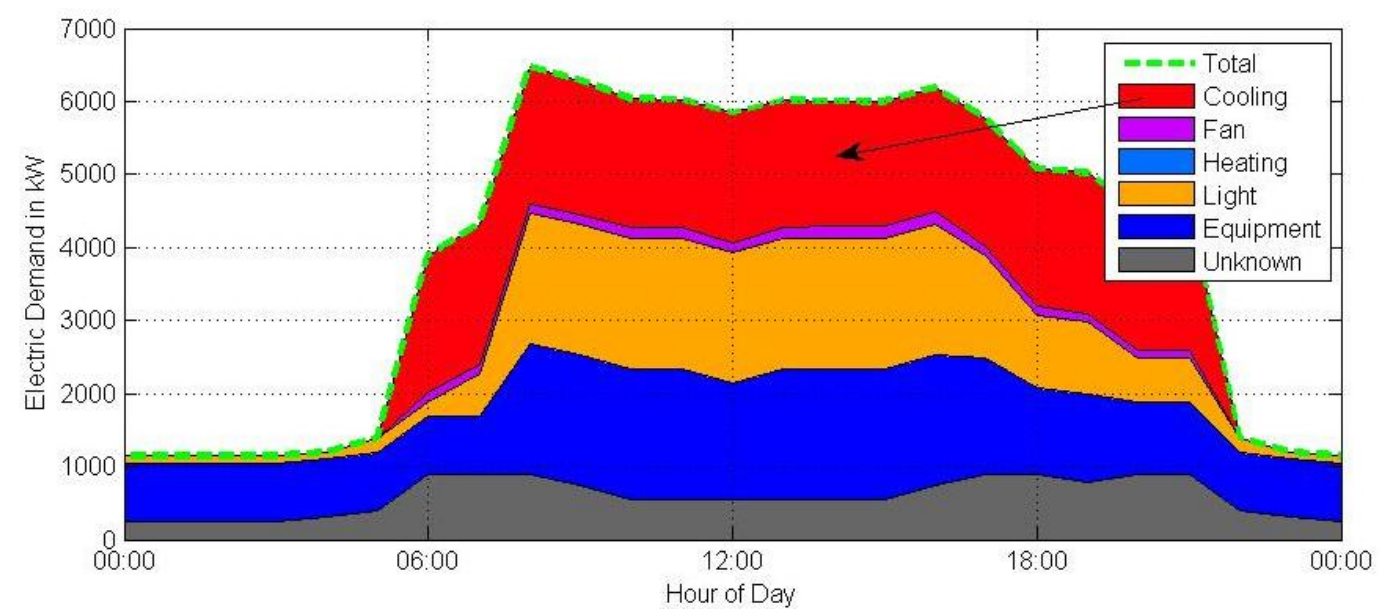

(a) Electric demand 


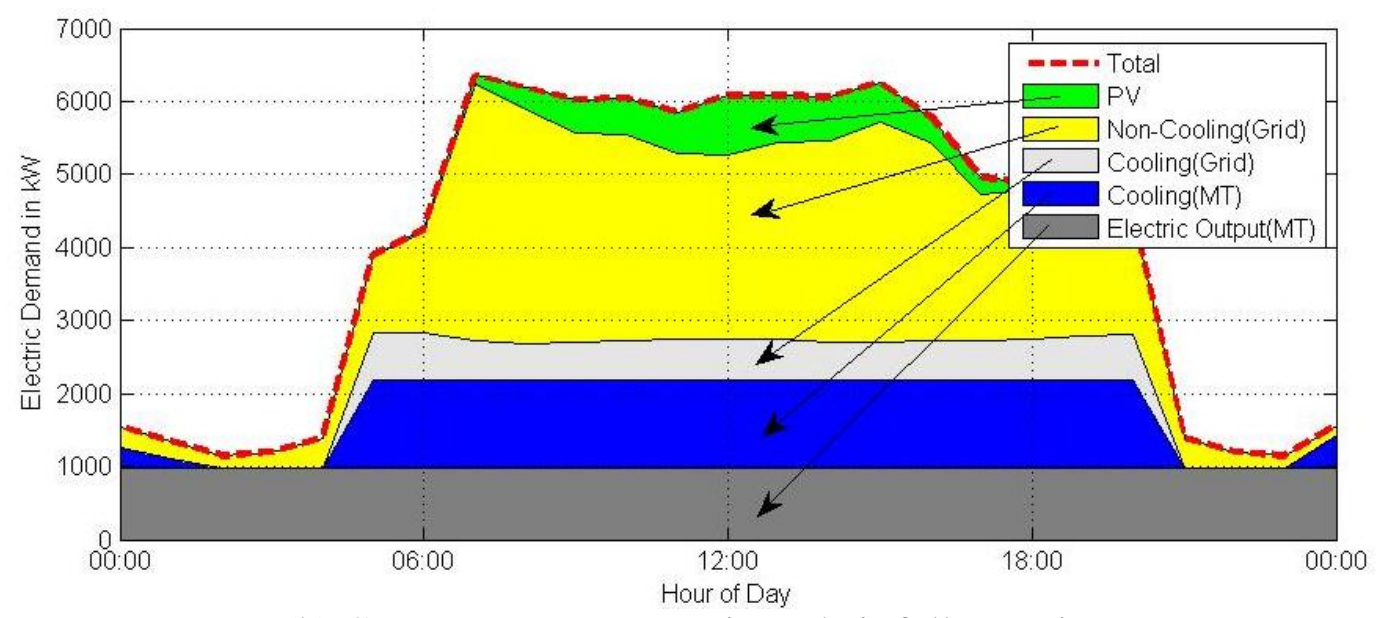

(b) Constant output scenario at their full capacity

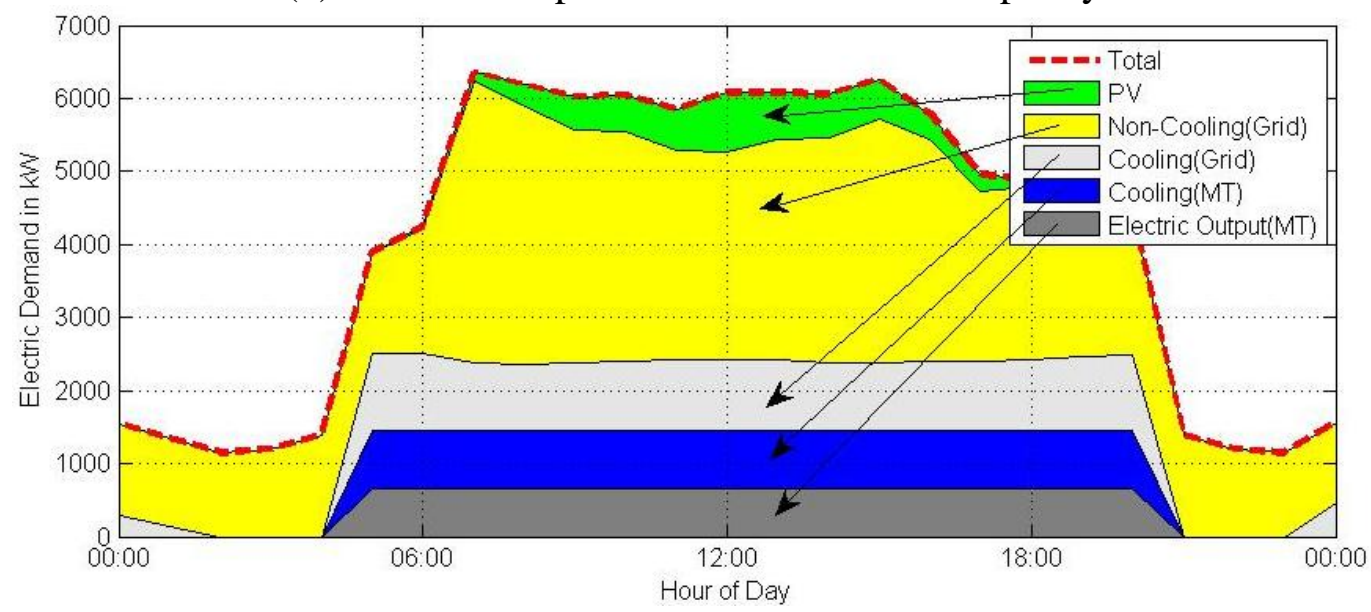

(c) Optimal output scenario

Fig. 12. Electric output (for base power) and chilled air output (for cooling demand) of $1565-\mathrm{kW}$ Capstone MTs for four large office buildings on an electric peak day, May 26, 2004.

Fig. 13 shows a thermal demand profile of four large office building customers in the Atlanta area on a thermal peak day, or February 13, 2004. In the constant output scenario at their full capacity in Fig. 13 (a), the fifteen MTs can produce a thermal output of 1,793.59 kW $(\approx 408,000$ BTUs $\times 15)$. Since they can provide sufficient thermal energy to meet the thermal demand before 5 a.m., mostly for heating on winter days, the system does not require heating energy from the central thermal utility (or the boiler). However, as the thermal demand rapidly increases after 5 a.m. (and the cooling demand decreases after 7 a.m.), the system produces more heating energy up to their full capacity. Then, to meet a thermal peak of $11,508.4 \mathrm{~kW}$, the system 
uses thermal energy from the central thermal utility. In the optimal output scenario in Fig. 13 (b), only ten MTs intermittently operate at peak hours, so they can produce a thermal output of $1,195.73 \mathrm{~kW}(\approx 408,000 \mathrm{BTUs} \times 10)$ and the system requires thermal energy from the central thermal utility to meet the thermal peak.

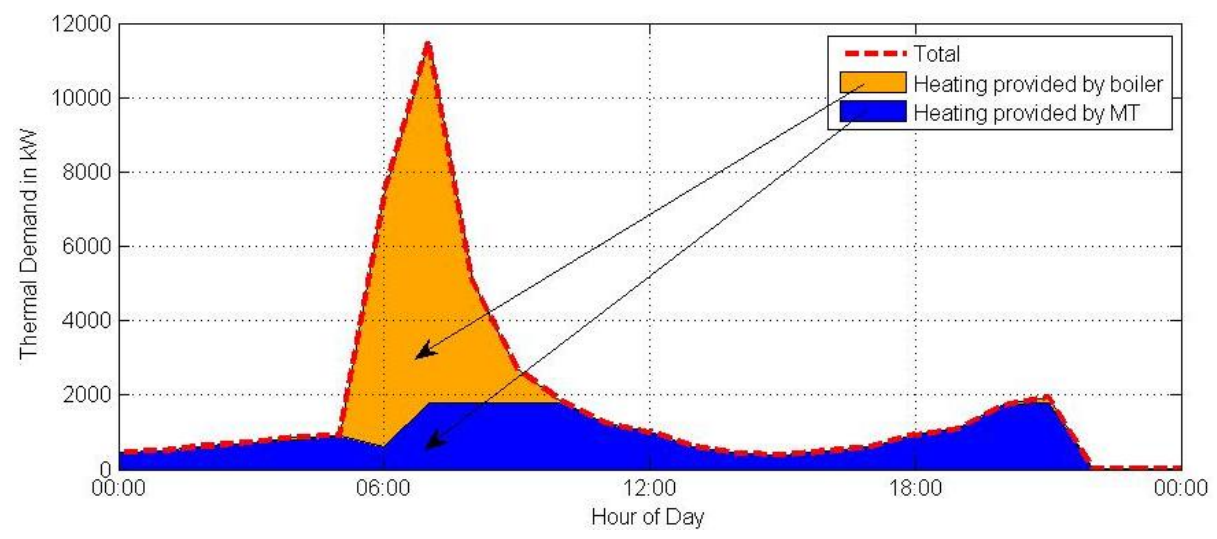

(a) Constant output scenario

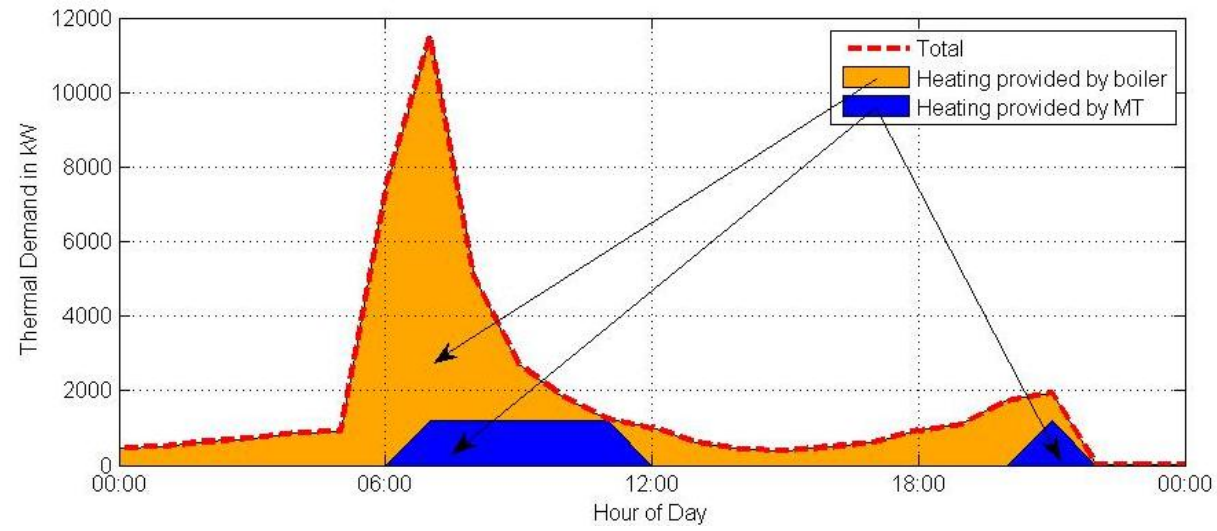

(b) Optimal output scenario

Fig. 13. Thermal output of 65-kW Capstone MTs for large office buildings on February 13, 2004.

After the simulations of operation of MTs during one year, an annual summary of electric energy purchased by the CCHP system is presented in Fig. 14. The thick bars of blue, red, and green correspond to the cases of small, medium, and large office building customers, respectively. The first, second, and third groups are for the scenario of with neither MTs nor PV, the constant operation of MTs (Full-Blast MTs and PVs), and the optimal operation of MTs (Optimal-Blast MTs and PVs), respectively. The full-blast operation of MTs for small, medium, and large office 
building customers reduces the annual electric energy purchased by the system by as much as 53.7, 69.1, and 55.1 percent, respectively. If MTs operate to minimize the generation costs, they reduce the annual electric energy by $14.5,16.8$, and 26.2 percent, respectively.

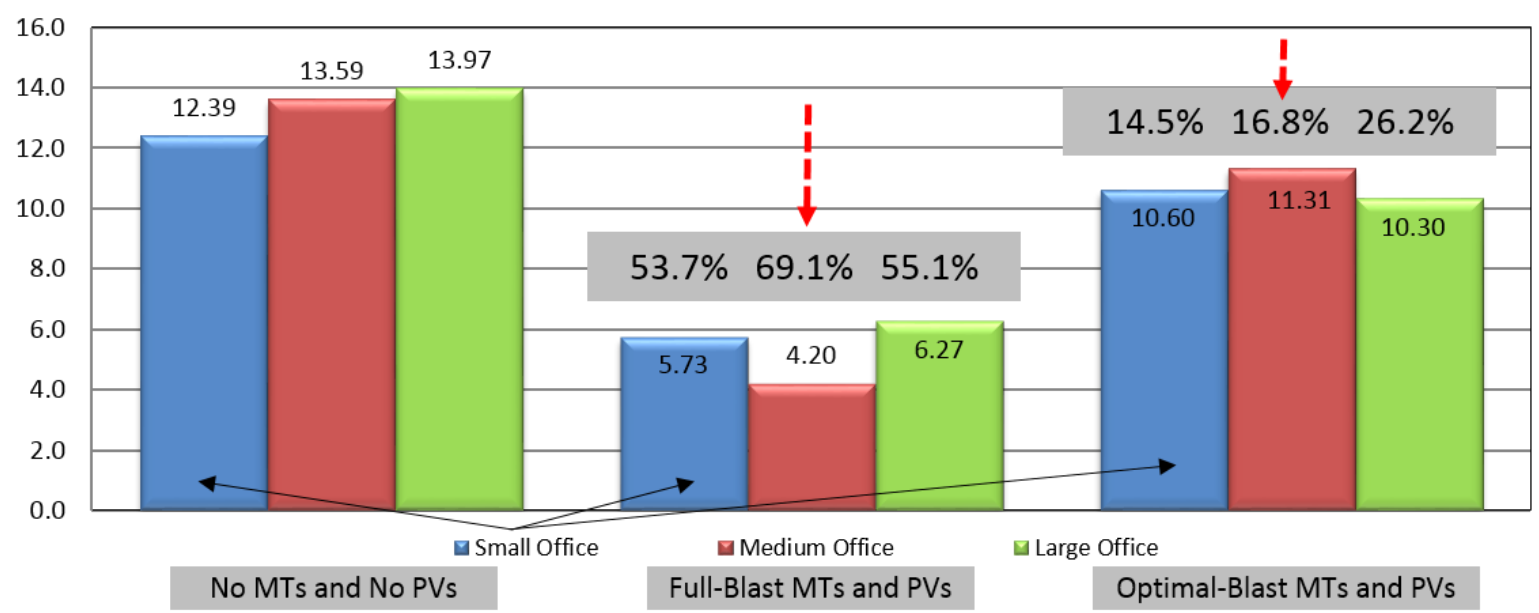

Fig. 14. Electric energy output for small, medium, and large office buildings purchased from the electric utilities in $\mathrm{kWh} / \mathrm{year} / \mathrm{ft}^{2}$.

\subsubsection{Generation Cost Changes}

The either constant or optimal operation of MTs reduces energy purchased from the electric and thermal utility, but a combination of MTs and PV systems may increase the costs of generating energy. A financial analysis on investment and operation costs of MTs and PV systems is performed by HOMER. It indicates that the PV systems and constantly operating MTs (Full-Blast MTs and PVs) increase the total generation costs for electric and thermal energy by 16.1-40.0 percent, in Fig. 15. However, MTs that optimally operate to minimize costs and PV systems increase the total generation costs by less than 9.5-26.2 percent. Fig. 15 indicates that a rise in the generation costs for large office building customers is the lowest than the other building types. Therefore, MTs and PV systems for large office building customers are relatively much 
more competitive for the other building types or net-zero energy building applications from the economic point of view.

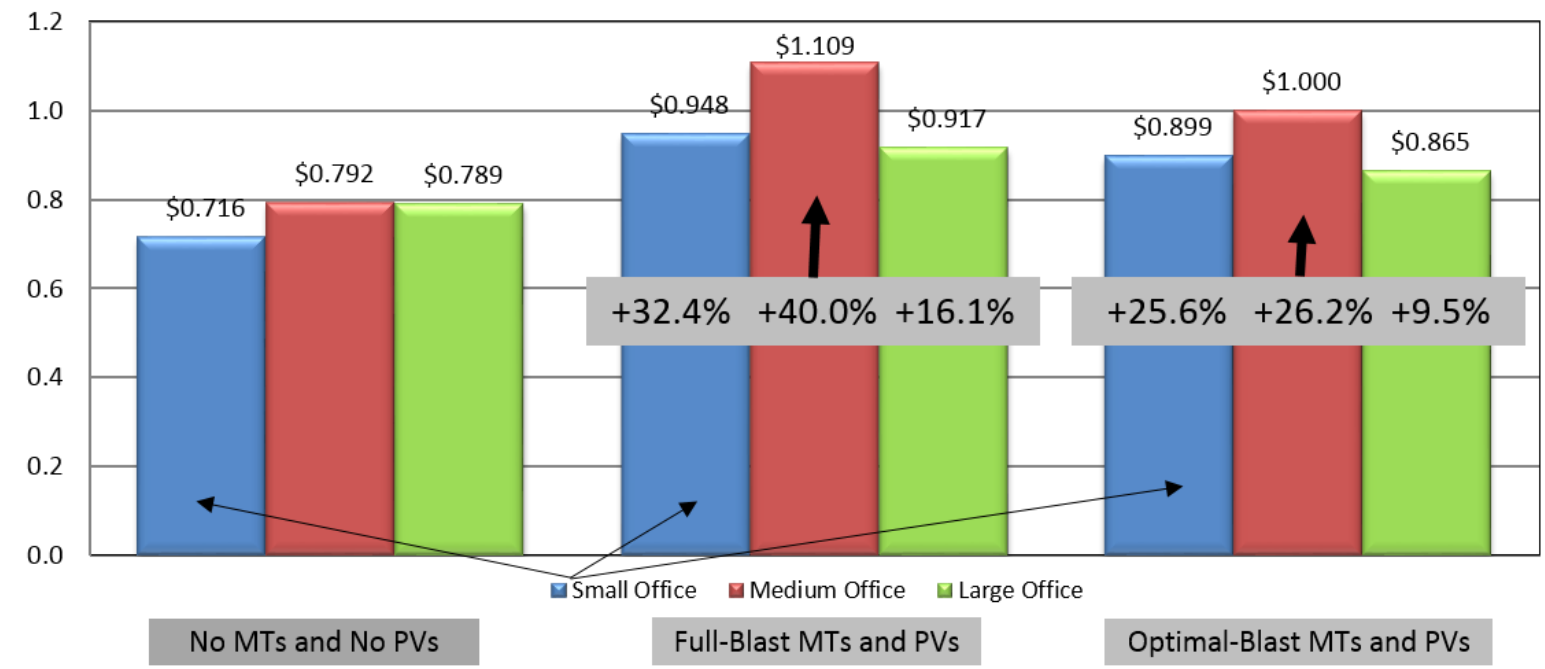

Fig. 15. Total annualized generation costs in $\$ / y e a r / \mathrm{ft}^{2}$ (including investment costs of CCHP and PV systems).

To examine the effect of the MTs and PV systems on an increase in total generation costs, an economic sensitivity analysis on the investment costs of the MTs and PV systems for large office building customers is performed by HOMER. Fig. 16 indicates that as the prices of natural gas decrease, in other words, as horizontally moving from the right to the left area, and the costs of generating electricity increase, in other words, as vertically moving from the lower to the upper area, MTs with relatively high capacity (e.g., up to $1000 \mathrm{~kW}$ ) are economical. For example, in the scenario of four large office building customers, the capacities of 600 to $700 \mathrm{~kW}$, pointed out by the white dotted arrows, are the most economical at a condition of a price of natural gas of 0.12 $\$ / \mathrm{m}^{3}$ and a cost of generating electricity of $0.042 \$ / \mathrm{kWh}$. In fact, since the average costs that generate electricity from PV are much more costly than those for MTs in TABLE IV, PV systems seem to increase the average generation costs. That is, installing PV systems on office buildings 
may not still be cost effective. However, the PV module prices have continuously decreased [44] and it will continue to decrease [46]. Therefore, it may be much more competitive for PV systems to install on net-zero energy office buildings.

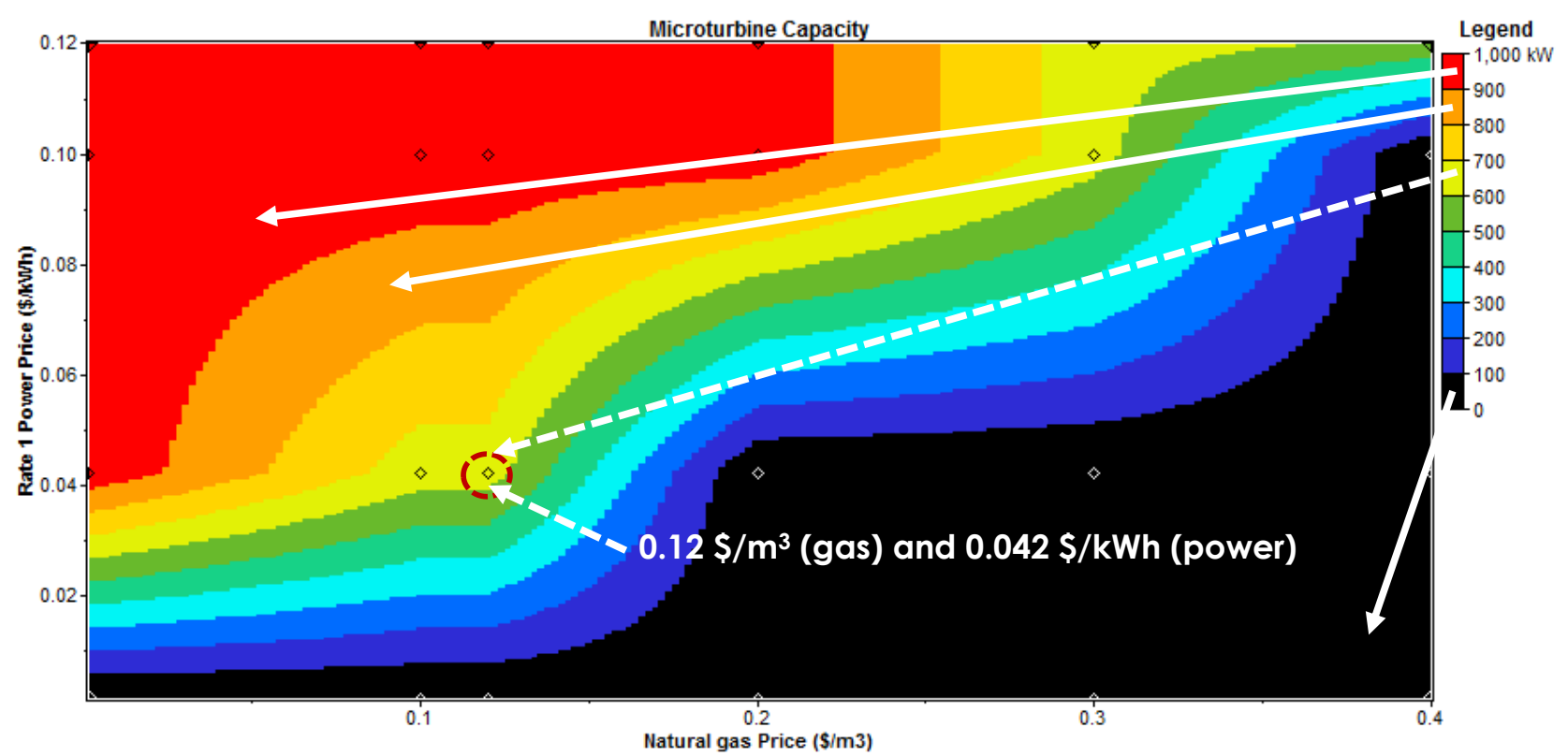

Fig. 16. The economic sensitivity analysis on investment costs of the MTs and PV systems for large office buildings.

\subsubsection{Environmental Impact}

The MTs and PV systems release less greenhouse gases and other pollutants because they decrease thermal and electric energy purchased from utilities. Fig. 17 indicates the annual effect of MTs and PV systems on water consumption. In fact, the MTs that constantly operate at their maximum capacity and PV systems for small, medium, and large office buildings reduce $\mathrm{CO}_{2}$, $\mathrm{NO}_{\mathrm{X}}, \mathrm{SO}_{2}$, and water consumption by as much as 19.2-26.1, 43.1-54.7, 20.6-27.3, and 52.8-67.0 percent, respectively. Thus, MTs in constant operation save much more emissions than MTs in optimal operation. 


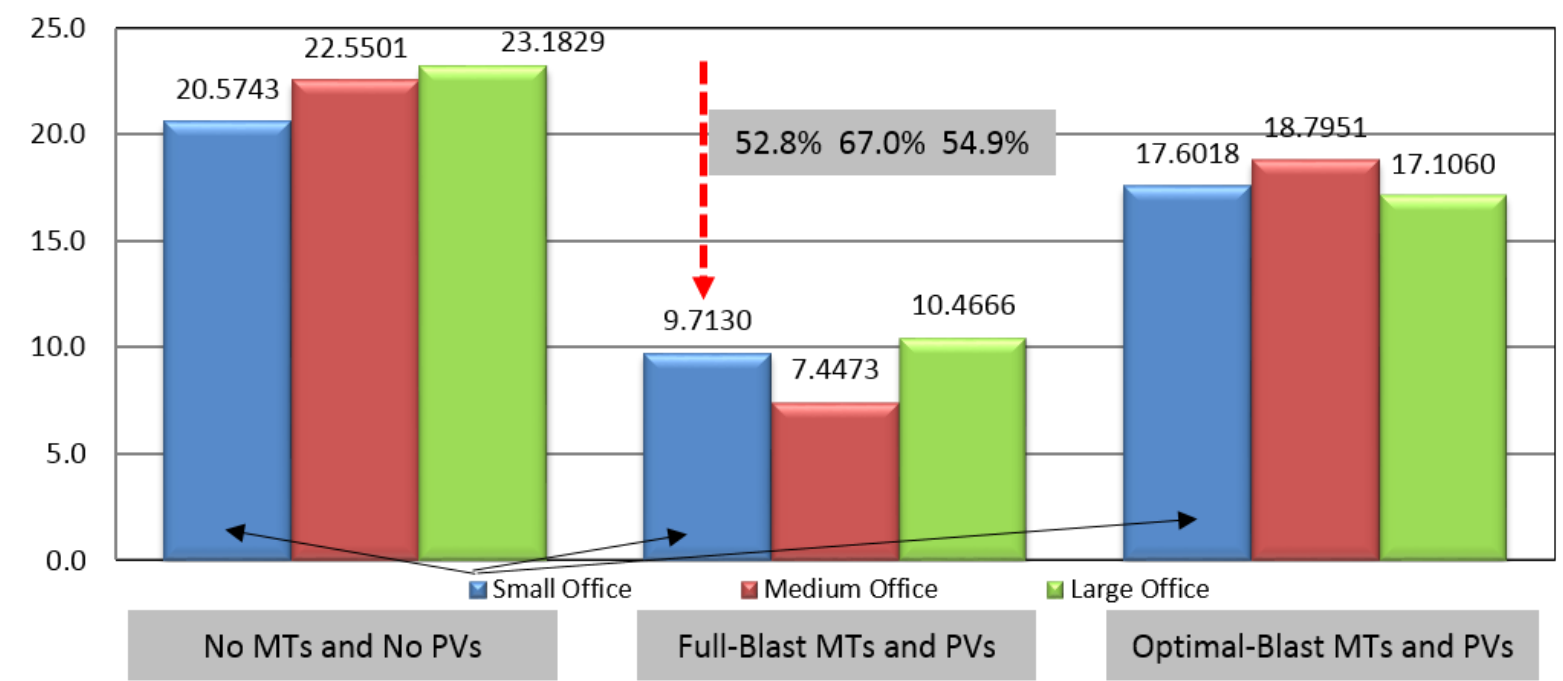

Fig. 17. Annual savings in water consumption.

\section{Conclusion}

The objective of this study was to present a case study that analyzes the impact of a CCHP (combined cooling heat and power) system using MTs (microturbines) with AbCs (absorption chillers) and PV (photovoltaic) systems on a reduction in: (a) energy consumption, (b) costs of generating electrical and thermal energy, (c) emissions (such as $\mathrm{CO}_{2}, \mathrm{NO}_{\mathrm{X}}$, and sulfur dioxide $\left[\mathrm{SO}_{2}\right]$ ), and (d) water consumption. For this purpose, this study has patterned the proposed simulation models based on case studies of residential and office building customers for the Atlanta area. It also collected electric and thermal load profile data for the area. Using HOMER, it scheduled the output of the electric and thermal grid for one year based on hourly demand. Finally, it analyzed the impact of the CCHP system for residential customers in the Atlanta area and CCHP and PV systems for office building customers in the area from the point of energy-efficient, economical, and environmental views.

From the results of case studies, it can be concluded that a combination of MTs with AbCs and PV systems could effectively reduce energy supplied from electric utilities, including peak-time generation that burns the most expensive fuel. In addition, the AbC could produce 
chilled air or water from waste heat to meet electrical cooling load during summer, including at peak hours. Therefore, it can maximize energy efficiency. Accordingly, MTs with AbCs could save more energy, thereby decreasing total generation costs. For example, this study illustrated that the optimal operation of MTs with AbCs (but without PV systems) for residential customers could decrease generation costs, especially by as much as 5.6 percent. But the economic sensitivity analysis of small, medium, and large office building customers hosting both PV systems and MTs showed an increase in overall generation costs. In fact, since such an increase in the costs of large office buildings is the lowest, MTs and PV systems for large office buildings are relatively more competitive against the other building types. Such an increase in the total generation costs causes from the more expensive energy generation costs of PV systems than those of conventional generation and MTs. However, since the generation costs of PV systems have been decreasing rapidly, PV systems for office buildings may be competitive against conventional generation units. Finally, the MTs could also decrease greenhouse gases and other pollutants emissions. For example, CCHP systems for residential customers in constantly operating at their full capacity can reduce electric energy use by 48.8 percent, costs (by 5.6 percent in the case of optimal operation), and pollutant emissions by 16.8 percent $\left(\mathrm{SO}_{2}\right), 38.1$ percent $\left(\mathrm{NO}_{\mathrm{X}}\right), 15.5$ percent $\left(\mathrm{CO}_{2}\right)$, and 48.6 percent (water consumption).

This study has found the effect of MTs with AbCs and PV systems of residential and office building customers on the improvement of the energy efficiency and an decrease in the generation costs. However, this study did not model the non-technical issues such as indoor comfort, policy incentive, and personal characteristics and the technical issues such as the costs of generating electricity different at peak times, dynamic pricing, energy efficiency, and storage systems such as batteries, heat, and cooling storage. In fact, excessive electric and thermal energy stored in such 
systems can be returned to the grid at peak hours, thereby more dramatically decreasing grid energy and the total generation costs. Therefore, our work could be extended to such cases by modeling the issues, which would allow us to identify the more accurate effect of CCHP and PV systems on building customers.

\section{Appendix}

TABLE V. Parameters for microturbines

\begin{tabular}{|c|c|c|}
\hline \multirow{2}{*}{\multicolumn{2}{|c|}{$\begin{array}{c}\text { Type } \\
\text { Lifetime (operating hours) }\end{array}$}} & $\mathrm{AC}$ \\
\hline & & 80,000 \\
\hline \multicolumn{2}{|r|}{ Minimum load ratio (\%) } & $60 \%$ \\
\hline \multicolumn{2}{|r|}{ Fuel } & Natural gas \\
\hline \multicolumn{2}{|r|}{ Heat recovery ratio $(\%)$} & 53.4 \\
\hline \multirow{5}{*}{ Emissions Factors } & Carbon monoxide $\left(\mathrm{g} / \mathrm{m}^{3}\right.$ of fuel $)$ & 6.5 \\
\hline & Unburned hydrocarbons $\left(\mathrm{g} / \mathrm{m}^{3}\right.$ of fuel) & 0.72 \\
\hline & Particulate matter $\left(\mathrm{g} / \mathrm{m}^{3}\right.$ of fuel $)$ & 0.49 \\
\hline & Proportion of fuel sulfur converted to PM (\%) & 2.2 \\
\hline & Nitrogen oxides $\left(\mathrm{g} / \mathrm{m}^{3}\right.$ of fuel $)$ & 58 \\
\hline
\end{tabular}

TABLE VI. Parameters for PV

\begin{tabular}{|c|c|c|}
\hline \multirow{4}{*}{} & Output current & DC \\
\cline { 2 - 3 } & Lifetime (years) & 30 \\
\cline { 2 - 3 } & Derating factor (\%) & 90 \\
\cline { 2 - 3 } & Slope (degrees) & 34 \\
\cline { 2 - 3 } & Azimuth (degrees W of S) & 0 \\
\cline { 2 - 3 } & Ground reflectance (\%) & 20 \\
\cline { 2 - 3 } & Tracking system & No Tracking \\
\cline { 2 - 3 } Inverter & Atlanta, GA, USA \\
\cline { 2 - 3 } & Location & 30 \\
\cline { 2 - 3 } & Inverter lifetime (years) & 95 \\
\cline { 2 - 3 } & Inverter efficiency (\%) & 75 \\
\cline { 2 - 3 } & Rectifier inputs (capacity relative to inverter (\%)) & 85 \\
\hline
\end{tabular}

TABLE VII. Parameters for electric grids

\begin{tabular}{|l|c|c|}
\hline \multirow{3}{*}{ Emissions Factors } & Carbon dioxide $(\mathrm{g} / \mathrm{kWh})$ & 990 \\
\cline { 2 - 3 } & Sulfur dioxide $(\mathrm{g} / \mathrm{kWh})$ & 2.74 \\
\cline { 2 - 3 } & Nitrogen oxides $(\mathrm{g} / \mathrm{kWh})$ & 1.34 \\
\hline
\end{tabular}

TABLE VIII. Parameters for boilers

\begin{tabular}{|c|c|}
\hline Fuel & Natural gas \\
\hline Efficiency (\%) & 85 \\
\hline
\end{tabular}


TABLE IX. Economic inputs

\begin{tabular}{|c|c|}
\hline Annual real interest rate (\%) & 8 \\
\hline Project lifetime (years) & 25 \\
\hline
\end{tabular}

\section{Acknowledgement}

The authors would like to acknowledge the financial support from the National Science Foundation through grants (\#0836046 and \#1441208), Brook Byers Institute for Sustainable Systems, Hightower Chair, and the Georgia Research Alliance at the Georgia Institute of Technology for this work.

\section{References}

[1] United States Department of Energy and Environmental Protection Agency, "Combined Heat and Power: A Clean Energy Solution,” Tech. Rep., 2012.

[2] Midwest CHP Application Center, "University of Michigan, 45.2 MW CHP Application," Tech. Rep. Available: http://www.midwestchptap.org/profiles/ProjectProfiles/UofMI.pdf

[3] D. Connolly, H. Lund, B. V. Mathiesen, and M. Leahy, "A review of computer tools for analysing the integration of renewable energy into various energy systems," Applied Energy, vol. 87, pp. 1059-1082, 2010.

[4] W. Gu, Z. Wu, R. Bo, W. Liu, G. Zhou, W. Chen, and Z. Wu, "Modeling, planning and optimal energy management of combined cooling, heating and power microgrid: A review," International Journal of Electrical Power \& Energy Systems, vol. 54, pp. 26-37, 2014.

[5] S. Bahramara, M.P. Moghaddam, and M.R. Haghifam, "Optimal planning of hybrid renewable energy systems using HOMER: A review," Renewable and Sustainable Energy Reviews, vol. 62, pp. 609-620, 2016.

[6] C. S. Chang and W. Fu, "Stochastic multiobjective generation dispatch of combined heat and power systems," IEE Proceedings of Generation, Transmission and Distribution, vol. 145, Issue 5, pp. 583-591, 1998.

[7] P. Derewonko and J. M. Pearce, "Optimizing design of household scale hybrid solar photovoltaic + combined heat and power systems for Ontario," 2009 34th Photovoltaic Specialists Conference, Philadelphia, USA, June 07-12, 2009.

[8] R. Hashemi, “A Developed Offline Model for Optimal Operation of Combined Heating and Cooling and Power Systems," IEEE Transactions on Energy Conversion, Vol. 24, Issue 1, pp. 222-229, 2009. 
[9] Z. Kan, P. Jianping, and C. Lin, "Optimal Combined Heat and Power system scheduling in smart grid," IEEE Conference on Computer Communications, Toronto, Canada, April 27-May 2, 2014.

[10] M. Geidl, G. Koeppel, P. Favre-Perrod, B. Klöckl, G. Andersson, and K. Fröhlich, "The Energy Hub - A Powerful Concept for Future Energy Systems," 3rd Annual Carnegie Mellon Conference on the Electricity Industry, Carnegie Mellon University, Pittsburgh, Pennsylvania, March 13-14, 2007.

[11] M. Schulze, L. Friedrich, and M. Gautschi, "Modeling and optimization of renewables: applying the Energy Hub approach,” 2008 IEEE International Conference on Sustainable Energy Technologies, SMU Conference Center Singapore, Singapore, Nov. 24-27, 2008.

[12] C. Marnay, M. Stadler, A. Siddiqui, N. DeForest, J. Donadee, P. Bhattacharya, and J. Lai, "Applications of optimal building energy system selection and operation," Journal of Power and Energy, vol. 227, pp. 82-93, 2013.

[13] M. Almassalkhi and I. Hiskens, "Cascade Mitigation in Energy Hub Networks," 50th IEEE Conference on Decision and Control and European Control Conference, Orlando, FL, USA, December 12-15, 2011.

[14] M. Almassalkhi and I. Hiskens, "Optimization Framework for the Analysis of Large-scale Networks of Energy Hubs," 17th Power Systems Computation Conference, Stockholm, Sweden, August 22-26, 2011.

[15] M. C. Bozchalui, S. A. Hashmi, H. Hassen, C. A. Canizares, and K. Bhattacharya, "Optimal Operation of Residential Energy Hubs in Smart Grids," IEEE Transactions on Smart Grid, Vol. 3, pp. 1755-1766, 2012.

[16] M. H. Amini, J. Frye, M. D. Ilic, and O. Karabasoglu, "Smart residential energy scheduling utilizing two stage Mixed Integer Linear Programming," 2015 North American Power Symposium, Charlotte, NC, USA, October 4-6, 2015.

[17] X. Tian and R. Zhao, "Energy Network Flow Model and Optimization Based on Energy Hub for Big Harbor Industrial Park,” Journal of Coastal Research, Vol. 73, pp. 298-303, 2015.

[18] X. Zhang, M. Shahidehpour, A. Alabdulwahab, and A. Abusorrah, "Optimal Expansion Planning of Energy Hub With Multiple Energy Infrastructures," IEEE Transactions on Smart Grid, Vol. 6, pp. 2302-2311, 2015.

[19] M. A. Bucher, T. W. Haring, F. Bosshard, and G. Andersson, "Modeling and economic evaluation of Power2Gas technology using energy hub concept," 2015 IEEE Power \& Energy Society General Meeting, Denver, USA, July 26-30, 2015.

[20] S. Bahrami and A. Sheikhi, "From Demand Response in Smart Grid Toward Integrated Demand Response in Smart Energy Hub," IEEE Transactions on Smart Grid, vol. 7, pp. 650-658, 2016. 
[21] A. Sheikhi, M. Rayati, S. Bahrami, and A. M. Ranjbar, "Integrated Demand Side Management Game in Smart Energy Hubs," IEEE Transactions on Smart Grid, vol. 6, pp. 675-683, 2015.

[22] H. Aki and A. Murata, "Combined Heat and Power Systems in Urban Commercial Building in China," 2005 IEEE/PES Transmission and Distribution Conference and Exhibition: Asia and Pacific, May 21-24, 2006.

[23] A. S. Rattner and S. Garimella, "Energy harvesting, reuse and upgrade to reduce primary energy usage in the USA," Energy, vol. 36. Issue 10, pp. 6172-6183, 2011.

[24] A. B. Little and S. Garimella, "Comparative assessment of alternative cycles for waste heat recovery and upgrade,” Energy, vol. 36. Issue 7, pp. 4492-4504, 2011.

[25] A. B. Little and S. Garimella, "Waste Heat Recovery in Data Centers Using Sorption Systems," Journal of Thermal Science and Engineering Applications, vol. 4, Issue 2, pp. 021007-021007, 2012.

[26] Homer Energy, User Manual of HOMER® Pro Version 3.7, 2016.

[27] T. Lambert, P. Gilman, and P. Lilienthal, "Micropower system modeling with HOMER," Integration of Alternative Sources of Energy, Wiley-IEEE Press, pp. 379-418, 2006.

[28] Capstone, "Global Case Studies - United States - East," Tech. Rep., 2015. Available from: http://www.capstoneturbine.com/company/global/region.asp?region=35

[29] J. H. Frankland, "A Model-Based Feasibility Study of Combined Heat and Power Systems for Use in Urban Environments," M.S. Thesis, School of Mechanical Engineering, Georgia Institute of Technology, 2013.

[30] Open energy information. Available from: http://en.openei.org/wiki/Main_Page

[31] Capstone, "Masonic Village," Tech. Rep., 2014. Available from: www.capstoneturbine.com/company/global/region.asp?region=35

[32] Statista, "Number of people per household in the United States from 1960 to 2013." Available from: www.statista.com/statistics/183648/average-size-of-households-in-the-us/

[33] M. T. Sheehan and T. Cleveland, "Small Generator Interconnection Procedures Screens," Solar America Board for Codes and Standards Report, July 2010.

[34] Georgia Power Company, “2010 Annual Report,” Tech. Rep., February 25, 2011.

[35] U.S. Department of Energy Office of Oil, Gas, and Coal Supply Statistics, "Natural Gas Annual 2012,” Tech. Rep., 2012.

[36] Capstone, "Office Building: 1350 Avenue of the Americas 1350 Avenue of the Americas," Tech. Rep., $2008 . \quad$ Available from: http://www.capstoneturbine.com/company/global/region.asp?region=35

[37] C. Roselund, "U.S. installed solar PV costs continue to fall," PV Magazine Global, September 18, 
2014.

[38] L. Lisell and G. Mosey, "Feasibility Study of Economics and Performance of Solar Photovoltaics at the Former St. Marks Refinery in St. Marks, Florida,” National Renewable Energy Laboratory, Tech. Rep., September, 2010.

[39] B. L. Capehart, "Microturbines," Whole Building Design Guide and National Institute of Building Sciences, 2010.

[40] M. Deru, K. Field, D. Studer, K. Benne, B. Griffith, P. Torcellini, B. Liu, M. Halverson, D. Winiarski, M. Rosenberg, M. Yazdanian, J. Huang, and D. Crawley, "U.S. Department of Energy Commercial Reference Building Models of the National Building Stock," National Renewable Energy Laboratory, Tech. Rep., February, 2011.

[41] SunShot Initiative and U.S. Department of Energy, "SunShot Vision Study," Tech. Rep., February, 2012.

[42] P. H. Gleick, "Annual Review of Energy and the Environment," Water and Energy, vol. 19, Issue 1, pp. 267-299, 1994.

[43] Environmental Protection Agency, "Combined Heat and Power: Frequently Asked Questions," Tech. Rep.

[44] I. Kim, "Impact of Stochastic Renewable Distributed Generation on Urban Distribution Networks," Ph.D. dissertation, Dept. Electrical and Computer Eng., Georgia Institute of Technology, Atlanta, 2014.

[45] National Renewable Energy Laboratory, National Solar Radiation Data Base. Available from: http://rredc.nrel.gov/solar/old_data/nsrdb/1991-2005/tmy3

[46] I. Kim, "The Recent Trends of Renewable Energy Sources for Power Generation in the United States," Engineering \& Technology Reference, 2015. 